\title{
Recent Development of Photocatalysts Containing Carbon Species: A Review
}

\author{
Zheng-Jun Shi ${ }^{1,2}$, Ming-Guo Ma ${ }^{3, * \mathbb{D}}$ and Jie-Fang Zhu ${ }^{4, *(D)}$ \\ 1 Key Laboratory of Forest Resources Conservation and Utilization in the Southwest Mountains of China, \\ Southwest Forestry University, Ministry of Education, Kunming 650224, China; \\ shizhengjun1979@swfu.edu.cn \\ 2 College of Chemical Engineering, Southwest Forestry University, Kunming 650224, China \\ 3 Engineering Research Center of Forestry Biomass Materials and Bioenergy, Beijing Key Laboratory of \\ Lignocellulosic Chemistry, College of Materials Science and Technology, Beijing Forestry University, \\ Beijing 100083, China \\ 4 Department of Chemistry, the Ångström Laboratory, Uppsala University, 75121 Uppsala, Sweden \\ * Correspondence: mg_ma@bjfu.edu.cn (M.-G.M.); jiefang.zhu@kemi.uu.se (J.-F.Z.); Tel.: +86-10-62337250 \\ (M.-G.M.); +46-18-4713722 (J.-F.Z.); Fax: +86-10-62336903 (M.-G.M.); +46-18-513548 (J.-F.Z.)
}

Received: 3 December 2018; Accepted: 24 December 2018; Published: 28 December 2018

check for updates

\begin{abstract}
Undoubtedly, carbon-based (nano)composites can be promising photocatalysts with improved photocatalytic activity due to the coupling effect from the incorporation of carbon species. In this mini-review, we focus on the recent development of photocatalysts based on carbon-based (nano)composites. $\mathrm{TiO}_{2}$ is well-known as a typical photocatalyst. Special attention is paid to the various types of carbon- $\mathrm{TiO}_{2}$ composites such as $\mathrm{C}$-doped $\mathrm{TiO}_{2}, \mathrm{~N}-\mathrm{C}$-doped $\mathrm{TiO}_{2}$, metal-C-doped $\mathrm{TiO}_{2}$, and other co-doped $\mathrm{C} / \mathrm{TiO}_{2}$ composites. Various synthetic strategies including the solvothermal/hydrothermal method, sol-gel method, and template-directed method are reviewed for the preparation of carbon-based $\mathrm{TiO}_{2}$ composites. C/graphitic carbon nitride $\left(\mathrm{g}-\mathrm{C}_{3} \mathrm{~N}_{4}\right)$ composites and ternary $\mathrm{C}$-doped composites are also summarized and ascribed to the unique electronic structure of $g-\mathrm{C}_{3} \mathrm{~N}_{4}$ and the synergistic effect of the ternary interfaces, respectively. In the end, we put forward the future perspective of the photocatalysts containing carbon species based on our knowledge.
\end{abstract}

Keywords: photocatalysts; C-doped; (nano)composites; $\mathrm{TiO}_{2} ; \mathrm{g}-\mathrm{C}_{3} \mathrm{~N}_{4}$; synergistic effect

\section{Introduction}

Photocatalysis has been widely used in many applications such as water splitting [1], energy conversion [2-4], and environmental remediation [5]. In recent years, environmental problems have attracted more and more attention. Obviously, photocatalysis is one of potential strategies for the degradation of pollutants, water treatment, and energy utilization [6-8]. Various materials including metal oxides [9-11], metal sulfides [12-14], graphitic carbon nitride ( $\mathrm{g}-\mathrm{C}_{3} \mathrm{~N}_{4}$ ) [15-17], and composites [18-20] have been reported as photocatalysts. Among these materials, composite photocatalysts have received special attention due to the synergistic effect from different components [21-23]. For example, the graphene/ $\mathrm{TiO}_{2}$ nanocomposite was reported to improve visible light photocatalytic activity, which displayed efficient visible light photocatalytic applications [24-26]. The incorporation of carbon species has been proven to be a promising strategy for improving the photocatalytic efficiency of composites, due to their high specific surface area, unique structure, or other properties [27-29]. Therefore, photocatalysts containing carbon species have been hot research materials for potential applications in environmental and energy fields.

This current mini-review gives an overview of the synthesis and photocatalytic properties of photocatalysts containing carbon species, especially C-doped $\mathrm{TiO}_{2}$. In Section 2, various methods 
including the solvothermal/hydrothermal method, sol-gel method, and template-directed method for the synthesis of $\mathrm{C}$-doped $\mathrm{TiO}_{2}$ are summarized. In addition, $\mathrm{C}$-doped $\mathrm{TiO}_{2}$ with pores such as mesoporous and hollow structures is introduced via typical examples. Finally, the existing problems, future development trends, and potential applications of these promising photocatalysts are put forward. We expect that this review would catch a glimpse of the current developments of these photocatalysts containing carbon species.

\section{Photocatalysts of C-doped $\mathrm{TiO}_{2}$}

\subsection{Photocatalysts of $\mathrm{TiO}_{2} / \mathrm{C}$ Composites}

Titanium dioxide $\left(\mathrm{TiO}_{2}\right)$ is well-known as a typical photocatalytic metal oxide. However, it displays low photocatalytic efficiency under visible-light irradiation due to its intrinsic large band gap. The incorporation of carbon species into $\mathrm{TiO}_{2}$ for the fabrication of C-doped $\mathrm{TiO}_{2}$ is a promising strategy for improving the photocatalytic efficiency, especially under visible light irradiation. In early 2006, Shanmugam et al. synthesized $\mathrm{TiO}_{2} @ \mathrm{C}$ core-shell composite nanoparticles in the range of $15-35 \mathrm{~nm}$ in a specially-made Swagelok cell at different temperatures [30]. They discovered that the $\mathrm{TiO}_{2} @ \mathrm{C}$ composites showed high photocatalytic activity for 4-chlorophenol degradation, compared with Degussa P25. Then, Sullivan et al. also presented visible light active C-doped $\mathrm{TiO}_{2}$ photocatalysts [31], displaying the activities in the oxidation of 4-chlorophenol under visible light irradiation. In their work, through the initial He heat treatments, one can tune the extent of graphitic carbon laydown. After that, $\mathrm{C}$ and $\mathrm{N}$ single and co-doping $\mathrm{TiO}_{2}$ films of single-layer electrodes were prepared as dye-sensitized solar cell devices [32], enhancing their short circuit current and efficiency, and improving the electron lifetime, charge transport, and recombination resistance. They achieved the highest cell efficiency of $10.2 \%$, as a result of a balance between the band gap, surface area, and diffused reflection of the photoanode. More recently, visible light active carbon-doped $\mathrm{TiO}_{2}$ with anatase/rutile multi-phases coated on granular activated carbon was applied to the removal of nonylphenol in solution [33]. They discovered the decreased band gap from $3.17 \mathrm{eV}$ to $2.72 \mathrm{eV}$ after C doping.

The solvothermal method is one traditional route for the synthesis of metal oxides. In the literature, the calcination-assisted solvothermal method was developed to fabricate the $\mathrm{C}-\mathrm{TiO}_{2}$ composites coupled with three colors (blue, green, and red) of emitting up-conversion phosphors [34], displaying the unique optical property via absorbing UV, visible, and near-infrared (NIR) lights. These composites exhibited photocatalytic activities for the degradation of rhodamine B (RhB) solution under NIR light irradiation and the destruction of continuous NO gas flow under the irradiation of UV, visible light-emitting diodes (LEDs), and infrared laser. It was found that the calculated photon efficiency under infrared light irradiation was much higher than those under UV and visible light irradiations, and the green light emitting up-conversion phosphor coupled $\mathrm{C}-\mathrm{TiO}_{2}$ composite presented the superior photocatalytic performance over the blue and red ones [34].

The solvothermal method was also applied to prepare $\mathrm{TiO}_{2} /$ graphene composites with a chemical bonding interface and enhanced photocatalytic activity in the photodegradation of formaldehyde in air using tetrabutyl orthotitanate as the $\mathrm{Ti}$ source [35]. As for the $\mathrm{TiO}_{2}$ /graphene nanocomposites with $2.5 \mathrm{wt} \%$ graphene, numerous $\mathrm{TiO}_{2}$ nanocrystals that were densely deposited onto the graphene sheets were obtained due to interfacial interactions and preferential heterogeneous nucleation (Figure 1a,b). One can observe the fringe spacing of ca. $3.51 \AA$ A matching the (101) crystallographic plane of anatase $\mathrm{TiO}_{2}$ (Figure 1d), exhibiting a high surface energy. Interestingly, in their work, they found the graphene content to exhibit an obvious influence on the photocatalytic activity and synergetic effect between graphene and $\mathrm{TiO}_{2}$ nanoparticles. The authors indicated that the $\mathrm{TiO}_{2} /$ graphene composite with chemical bonding caused an intimate interaction between $\mathrm{TiO}_{2}$ nanoparticles and graphene nanosheets (Figure 2a). The formation of a C-Ti bond significantly contributed to the enhanced photocatalytic activity of the $\mathrm{TiO}_{2}$ /graphene composite. It is energetically feasible to transfer the photogenerated 
electrons on the conduction band (CB) of $\mathrm{TiO}_{2}$ to graphene (Figure 2b). It was reported that the energy level of the valence band (VB) is $2.81 \mathrm{~V}$, the energy level of the conduction band (CB) is $-0.39 \mathrm{~V}$, and the calculated Fermi energy level of graphene is $-0.08 \mathrm{~V}$ versus a normal hydrogen electrode, respectively. The authors suggested that the design of new heterogeneous photocatalysts can be applied in environmental protection, water splitting, and photoelectrochemical conversion.

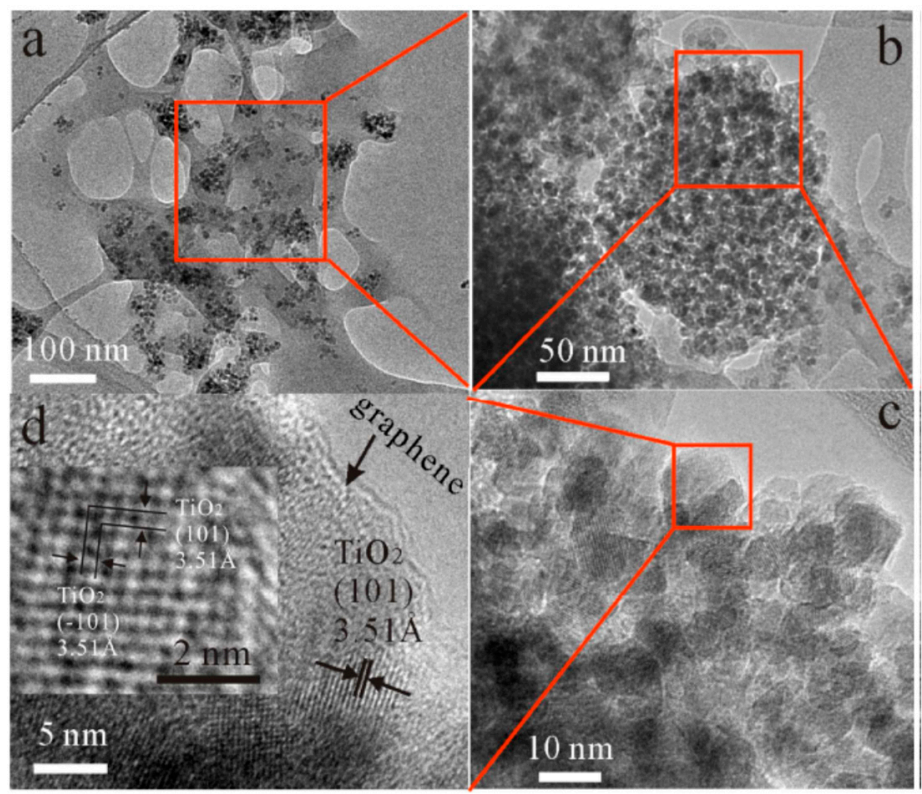

Figure 1. (a,b) TEM and (c,d) HR-TEM images of $\mathrm{G}_{2.5}-\mathrm{TiO}_{2}$ nanocomposite. From Ref. [35]. Reprinted with permission from American Chemical Society (ACS).

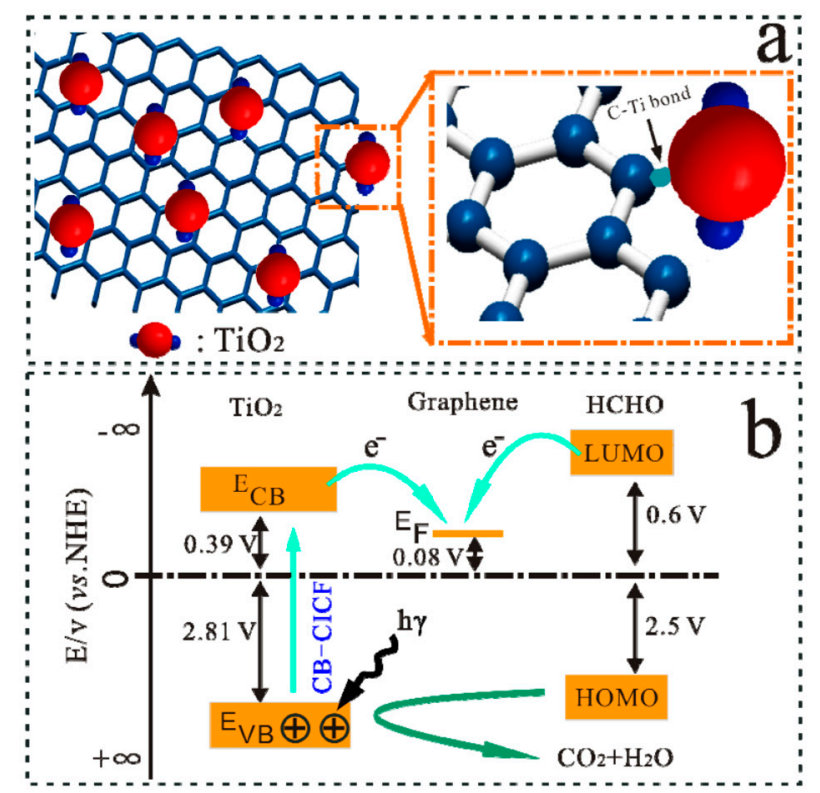

Figure 2. Schematic illustrations for the interfacial charge transfer effect in $\mathrm{TiO}_{2}$ /graphene composites: (a) the chemical bonding between $\mathrm{TiO}_{2}$ nanoparticles and graphene nanosheets; (b) the reported energy level of the valence band (VB) and conduction band (CB) vs. NHE (normal hydrogen electrode). From Ref. [35]. Reprinted with permission from ACS.

There have been a few reports on the synthesis of $\mathrm{C}$-doped $\mathrm{TiO}_{2}$ composites via the sol-gel method. For example, the sol-gel method was applied to prepare the core-shell structure of $\mathrm{TiO}_{2}$-carbon nanoparticles by utilizing the organic group in the Ti precursor [36]. One can observe the core-shell 
morphology with a 1.5-nm thick amorphous carbon layer, acting as a barrier on the grain boundary to obstruct the growth of anatase $\mathrm{TiO}_{2}$, resulting in a decrease in its crystal size of nine nm (Figure 3a-c). The Electron Energy Loss (EELS) spectra showed an average decrease in the Ti valence state in both $\mathrm{C} / \mathrm{TiO}_{2}$ and reduced $\mathrm{TiO}_{2}$ (Figure 3d). They reported a large number of oxygen vacancies for these materials, inducing the valence band tails, to enhance visible light absorption. The $\mathrm{C} / \mathrm{TiO}_{2}$ showed excellent solar-driven photocatalytic activities on the photodegradation of phenol and methyl blue, and an excellent hydrogen generation rate, which was 10 times higher than that of the reference $\mathrm{TiO}_{2}$ by photosplitting water.
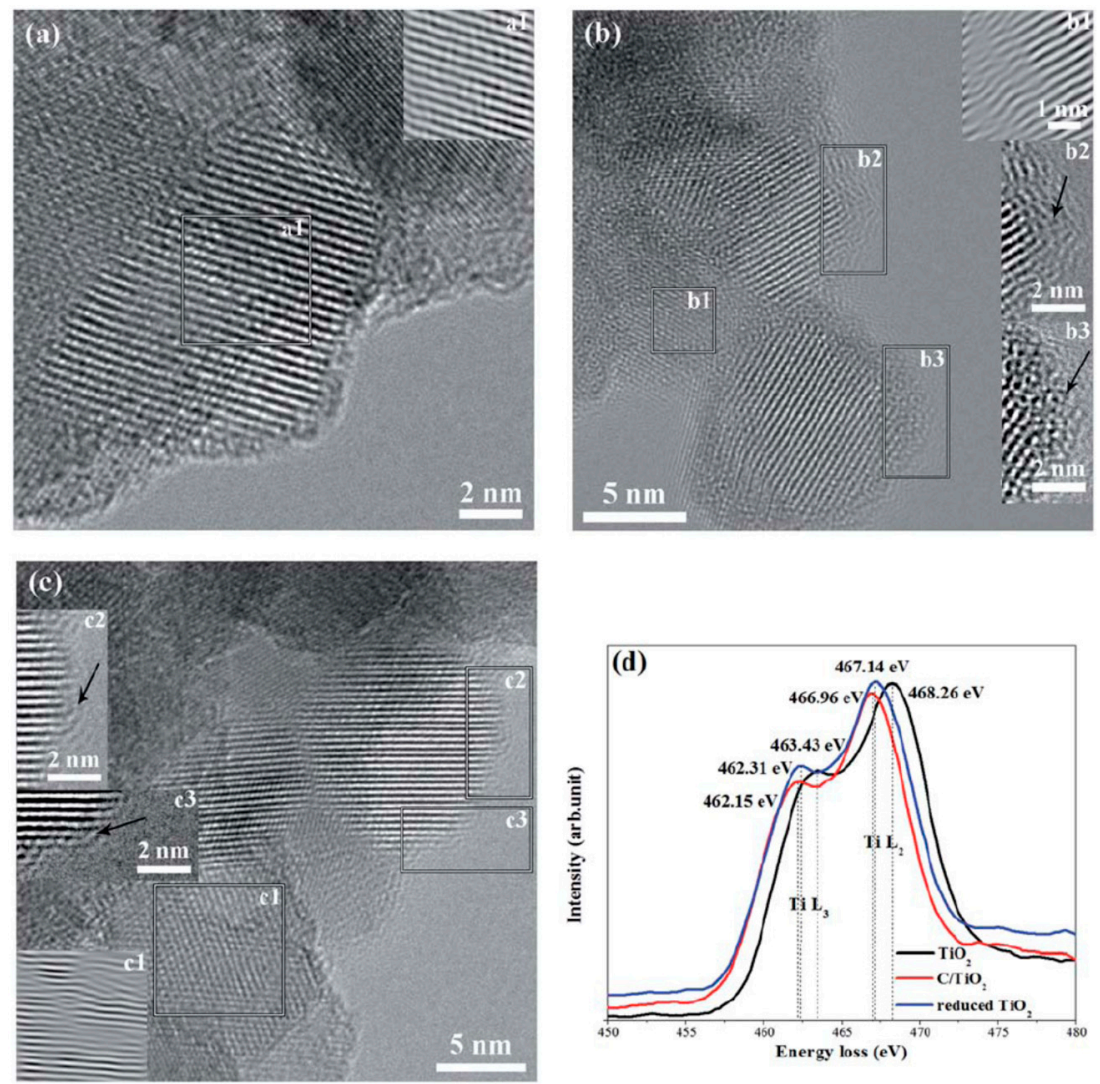

Figure 3. HR-TEM micrographs of (a) reference $\mathrm{TiO}_{2},(\mathbf{b}) \mathrm{C} / \mathrm{TiO}_{2}$, and (c) reduced $\mathrm{TiO}_{2}$, along with Fourier-filtered images (a1, b1, and c1) of selected areas and local enlarged images (b2, b3, c2, and c3) shown as inserts. (d) Electron Energy Loss (EELS) spectra of the Ti-L $2 ; 3$ edge for the three samples. From Ref. [36]. Reprinted with permission from Royal Society of Chemistry (RSC).

The sol-gel method was also used to synthesize $\mathrm{TiO}_{2} / \mathrm{C}$ nanosheets with a unique, multi-layer, cross-linked hole structure via the assistance of 1-butyl-3-methylimidazolium tetrafluoroborate ([Bmim] $\left.\left[\mathrm{BF}_{4}\right]\right)$, which is a polymerization of aniline and carbonization [37]. They discovered that the $\mathrm{TiO}_{2} / \mathrm{C}$ nanosheets showed an amazing photocatalytic capacity under both UV and sunlight irradiations due to C-doping, as well as a unique morphology, structure, and mixed phases of anatase and rutile, with high crystallization. The sol-gel method was developed to prepare a C-doped $\mathrm{TiO}_{2}$ catalyst for the visible light-induced photocatalytic degradation of ethylene [38]. They evaluated the effects of key parameters such as the visible light intensity, temperature, and feed composition (ethylene, oxygen, and water vapor) on the photocatalytic reaction rate. They indicated that the oxidation rate of ethylene was improved significantly with an increase of the visible light intensity, temperature, and oxygen and ethylene concentrations. Hassan et al. applied a modified sol-gel route to synthesize $\mathrm{C}-\mathrm{TiO}_{2}$ thin films based on the self-assembly technique, exploiting Tween 80 as a pore directing agent and carbon source [39]. It was reported that the addition of carbon enhanced 
the photocatalytic activity of $\mathrm{TiO}_{2}$ for methyl orange degradation under visible light irradiation. Recently, an in situ modified sol-gel method was used to synthesize the mesoporous C-doped $\mathrm{TiO}_{2}$ crystals with an average grain size of $22 \mathrm{~nm}$ and oxygen vacancy by the limited-oxygen atmosphere originating from the decomposition of urea [40]. These materials displayed $97.3 \%$ removal efficiency of RhB in nine minutes under UV light, and they also showed the complete RhB degradation under natural sunlight irradiation.

The porous structure is of great importance for increasing and improving the photoactivity of $\mathrm{C}$-doped $\mathrm{TiO}_{2}$ nanomaterials due to their large surface area and pore volume. In the previous literature, the mesoporous C-doped anatase $\mathrm{TiO}_{2}$ nanomaterials with excellent visible light photocatalytic activity in the degradation of toluene in the gas phase were synthesized by a one-step "green" synthetic approach with low-cost inorganic $\mathrm{Ti}\left(\mathrm{SO}_{4}\right)_{2}$ and glucose as precursors [41]. They indicated that the new electronic states above the valence band edge were directly responsible for the electronic origin of the band gap narrowing and visible light photoactivity of the C-doped $\mathrm{TiO}_{2}$. After that, mesoporous C-doped anatase $\mathrm{TiO}_{2}$ nanomaterials were also prepared by a one-pot green synthetic approach and post-thermal treatment using sucrose as a carbon-doping source [42]. The enhancement effect of post-thermal treatment between $100-300{ }^{\circ} \mathrm{C}$ was proved by the photodegradation of gas-phase toluene. The promoting effect of the post-thermal treatment can be attributed to the changes of the catalysts' surface and optical properties. The recombination of electron-hole pairs is effectively inhibited after thermal treatment due to the reduction of surface defects.

Zhou et al. synthesized uniformly carbonaceous and nitrogenous species sensitized $\mathrm{TiO}_{2}$ quantum dots employing an oleic acid and oleylamine system and the mesoporous structure of $\mathrm{C} / \mathrm{N}-\mathrm{TiO}_{2}$ nanospheres with significantly enhanced photocatalytic activity via an emulsion-based bottom-up self-assembly [43]. They obtained the narrow size distribution of monodisperse $\mathrm{C} / \mathrm{N}-\mathrm{TiO}_{2}$ quantum dots at an average size of $3.8 \mathrm{~nm}$ due to the effect of oleylamine and oleic acid, and mesostructured $\mathrm{C} / \mathrm{N}-\mathrm{TiO}_{2}$ nanospheres ranging from $100 \mathrm{~nm}$ to $300 \mathrm{~nm}$ in diameter, which were composed of these $\mathrm{C} / \mathrm{N}-\mathrm{TiO}_{2}$ quantum dots. Moreover, the mesoporous structure of the $\mathrm{C} / \mathrm{N}-\mathrm{TiO}_{2}$ nanospheres was stable in the degradation reactions irradiated by visible light. By measuring the photodegradation of $\mathrm{RhB}$ under visible light irradiation, they reported the water miscible mesostructured $\mathrm{C} / \mathrm{N}-\mathrm{TiO}_{2}$ nanospheres with improved catalytic area and RhB adsorption, and a red shift of the absorption edge to the visible light region, possessing improved photocatalytic activity.

The template-directed method has been a promising strategy for the synthesis of hollow structures. In Shi's work, carbon-doped $\mathrm{TiO}_{2}$ hollow spheres with a unique three-dimensional network structure and high visible light photocatalytic activity were synthesized using carbon spheres as the template [44]. By the decoration of methylene blue solution under visible light irradiation, carbon-doped $\mathrm{TiO}_{2}$ hollow spheres were reported to possess higher visible light-induced photocatalytic activity than commercial P25, which could be attributed to their visible light absorption characteristic created by C-doping and the unique hollow three-dimensional network structure. The template-directed self-assembly and calcination method was also explored to create C-doped hollow $\mathrm{TiO}_{2}$ spheres in situ [45]. The hollow and porous structure, as well as a highly ordered and well-defined morphology, were obtained. A number of broken spheres were observed in the sample prepared using one gram of tetrabutyl orthotitanate. The hollow sphere had the uniform shell thickness of $\sim 20 \mathrm{~nm}$ in the sample prepared using two grams of tetrabutyl orthotitanate (Figure $4 a, b)$. Increasing the amount of tetrabutyl orthotitanate to three grams, four grams, and five grams, hollow $\mathrm{TiO}_{2}$ spheres with shell thickness of $\sim 29 \mathrm{~nm}$ (Figure $4 \mathrm{c}, \mathrm{d}$ ), $45 \mathrm{~nm}$ (Figure 4e,f), and $59 \mathrm{~nm}$ (Figure 4g,h) were obtained, respectively. C-doped hollow $\mathrm{TiO}_{2}$ spheres, as photocatalysts for the degradation of $\mathrm{RhB}$ under visible light irradiation, exhibited a superior photocatalytic activity to commercial P25 and pure $\mathrm{TiO}_{2}$-based photocatalysts. 


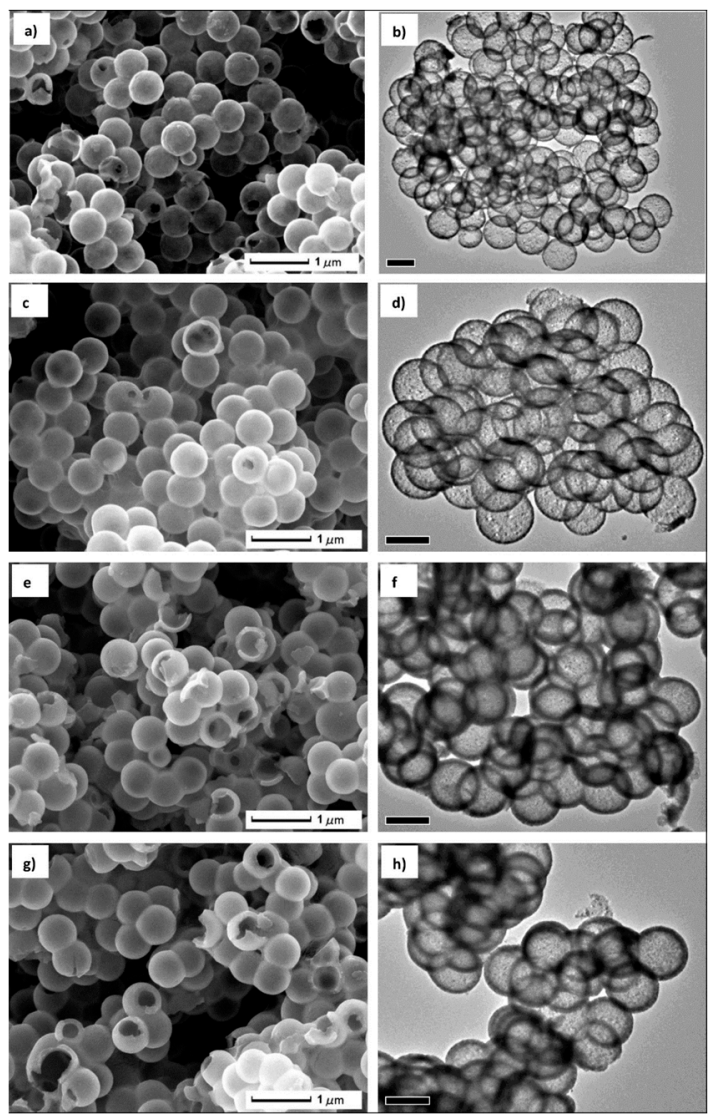

Figure 4. SEM and TEM images of the $\mathrm{C}$-doped hollow $\mathrm{TiO}_{2}$ spheres produced with different amounts of tetrabutyl orthotitanate: (a,b) 2 g; (c,d) 3 g; (e,f) 4 g; and (g,h) 5 g. From Ref. [45]. Reprinted with permission from Elsevier.

Using a multi-walled carbon nanotube mat as a "rigid" template and carbon-doping source, a C-doped mesoporous anatase $\mathrm{TiO}_{2}$ with a high surface area was obtained [46]. $\mathrm{TiO}_{2}$ nanoparticles have an average diameter of $10 \mathrm{~nm}$, surface area of $112-129 \mathrm{~m}^{2} \mathrm{~g}^{-1}$, and total pore volume of $0.74-0.85 \mathrm{~m}^{2} \mathrm{~g}^{-1}$. Using banana (Musa acuminata) stem fiber as a sacrificial template, visible light active C-doped mesoporous anatase $\mathrm{TiO}_{2}$ multi-tubes with highly improved visible light photocatalytic activity were synthesized [47]. The as-obtained materials showed a high surface area of $99 \mathrm{~m}^{2} \mathrm{~g}^{-1}$, a mesoporous structure made of $15 \pm 3 \mathrm{~nm}$ nanoparticles, an enhanced light absorption property in the whole visible light region, good thermal stability of the anatase phase up to $750{ }^{\circ} \mathrm{C}$, and an excellent photocatalytic activity for the reduction of $\mathrm{Cr}(\mathrm{VI})$ to $\mathrm{Cr}(\mathrm{III})$ under the visible light exposure.

Recently, carbon composites derived from different environmentally friendly renewable biomass attracted considerable attention due to their unique properties and wide applications [48-50]. Liu et al. fabricated visible light-active $\mathrm{C} / \mathrm{TiO}_{2}$ composites by the calcination method using $\mathrm{C}_{16} \mathrm{H}_{36} \mathrm{O}_{4} \mathrm{Ti}$ as the titanium source and bamboo powder with different sizes as the carbon source [51]. The as-obtained composites displayed the photocatalytic activities both under visible light irradiation and UV irradiation. After four cycles, bamboo $\mathrm{C} / \mathrm{TiO}_{2}$ composites still exhibited high stability. Moreover, they prepared biomass charcoal-doped titanium dioxide $\left(\mathrm{C} / \mathrm{TiO}_{2}\right)$ composites by the microwave-hydrothermal and calcination methods using tetrabutyl titanate as the titanium source and lignin as the carbon source [52]. The composites had a large BET-specific surface area of $203.58 \mathrm{~m}^{2} \mathrm{~g}^{-1}$, a total pore volume of $0.16 \mathrm{~cm}^{3} \mathrm{~g}^{-1}$, and an average pore diameter of $22.9 \mathrm{~nm}$. Experimental results indicated that both the microwave-hydrothermal temperature and time played an important role in the microstructure and photocatalytic activity. The core-shell structured CdS-decorated $\mathrm{TiO}_{2} /$ carbon microspheres were synthesized with controlled hydrolysis and the sonochemical method [53]. The pure 
commercial $\mathrm{TiO}_{2}$ had only the degradation efficiency of $4.96 \%$ for the $\mathrm{RhB}$, and the $\mathrm{TiO}_{2} /$ carbon reached $18.92 \%$, while the CdS-decorated $\mathrm{TiO}_{2} /$ carbon microspheres achieved $95.24 \%$ under visible light irradiation.

\subsection{Photocatalysts of $\mathrm{N}-\mathrm{C}$-Doped $\mathrm{TiO}_{2}$}

In comparison with C-doped $\mathrm{TiO}_{2}$ composites, $\mathrm{N}-\mathrm{C}$-doped $\mathrm{TiO}_{2}$ composites have been found to exhibit improved photocatalytic activity. Wang and Lim synthesized a highly visible light photoactive carbon and nitrogen co-doped $\mathrm{TiO}_{2}$ with well-developed mesoporosity and a large BET surface area of $102 \mathrm{~m}^{2} \mathrm{~g}^{-1}$ via the solvothermal method [54], and they used these photocatalysts for bisphenol A degradation in a photoreactor irradiated with flexible strips of visible light-emitting diode lights. They reported that under five hours of irradiation with white, blue, green, and yellow light-emitting diode lights, the extents of bisphenol A degradation were $>99 \%,>99 \%, 84 \%$, and $24 \%$, respectively, while the corresponding percentages of mineralization were $70 \%, 60 \%, 45 \%$, and $9 \%$, respectively. The hydrothermal method was developed to synthesize the nitrogen and carbon co-doped titanium dioxide photocatalysts using nitrogen from ammonia and carbon from alcohols with different chain lengths (methanol, ethanol, isopropanol, 1-butanol, 2-butanol, and tertrabutanol) as carbon precursors [55]. The authors observed the increasing activity of phenol decomposition with the chain length of the alcohol precursor. They discovered that the highest intrinsic photoactivity for $\mathrm{N}$ and $\mathrm{C}$ co-doped $\mathrm{TiO}_{2}$, which was prepared from 2-butanol and 1-butanol as carbon precursors, exhibited a strong resistance to deactivation during multiple catalyst reuse compared with pristine $\mathrm{TiO}_{2}$ and commercial Degussa P25 photocatalysts. In Xu et al.'s work, the hydrothermal treatment was employed to prepare $\mathrm{N}$-doped $\mathrm{TiO}_{2} / \mathrm{C}$ nanocomposites with high visible light photocatalytic activity in the presence of L-lysine as a ligand to control the nanocrystal growth and a source of nitrogen and carbon [56]. As-prepared nanocomposites had improved absorption in the visible light region and exhibited a higher photocatalytic activity, compared with pure $\mathrm{TiO}_{2}$, commercial P25, and previously reported $\mathrm{N}$-doped $\mathrm{TiO}_{2}$ photocatalysts. The molar ratio of $\mathrm{L}$-lysine/ $\mathrm{TiCl}_{4}$ and the $\mathrm{pH}$ value were found to be the important factors affecting the photocatalytic activity of the $\mathrm{N}-\mathrm{TiO}_{2} / \mathrm{C}$ composites.

The peptization-reflux method was reported to synthesize visible light-activated $\mathrm{C}-\mathrm{N}-\mathrm{TiO}_{2}$ with a diameter of ca. $7 \mathrm{~nm}$ at $120^{\circ} \mathrm{C}$ [57], showing a shift of the absorption edge to a lower energy, a stronger absorption in the visible region, and much higher photocatalytic activity for methyl orange degradation under visible light irradiation, compared to $\mathrm{TiO}_{2}$. Authors suggested that it could be assigned to the synergistic effect between the retained alkoxyls and the nitrogen doping. The mild one-step approach was adopted to prepare $\mathrm{N}$-doping carbon- $\mathrm{TiO}_{2}$ nanohybrids [58]. Before calcination, a morphism crystal phase was obtained. After calcination, the crystalline structure of the anatase phase and the characteristic peak for $\mathrm{C}$ at $26.2^{\circ}$ were observed in an XRD pattern (Figure 5a). The XPS spectrum exhibits C1s, O1s, N1s, Ti2p, and Cu2p3/2 (substrate) peaks after calcination (Figure 5b). One can observe the formed $\mathrm{N}-\mathrm{TiO}_{2}$ with an average diameter of eight $\mathrm{nm}$ and the nicely distributed of the $\mathrm{N}$-carbon dots on $\mathrm{N}-\mathrm{TiO}_{2}$ via TEM (Figure $5 \mathrm{c}$ ), and the junction between $\mathrm{N}-$ carbon and $\mathrm{N}-\mathrm{TiO}_{2}$ (Figure 5d). The N-doping carbon- $\mathrm{TiO}_{2}$ had a large BET specific surface area of $279.43 \mathrm{~m}^{2} \mathrm{~g}^{-1}$, a pore volume of $0.5750 \mathrm{~cm}^{3} / \mathrm{g}$, and a pore area of $96.66 \mathrm{~m}^{2} / \mathrm{g}$ (Figure $6 \mathrm{a}$ ). N-doping carbon- $\mathrm{TiO}_{2}$ nanohybrids displayed an absorption in the visible band, while P25 showed the band gap absorption onset at $380 \mathrm{~nm}$ (Figure 6b). N-doping carbon- $\mathrm{TiO}_{2}$ nanohybrids also had high re/oxidative current peaks, compared with that of P25 (Figure 6c). These N-doping carbon- $\mathrm{TiO}_{2}$ nanohybrids showed excellent photocatalytic ability towards organic $(\mathrm{RhB})$ and inorganic pollutant $\left(\mathrm{K}_{2} \mathrm{Cr}_{2} \mathrm{O}_{7}\right)$ degradations under visible light irradiation (Figure 6d). 

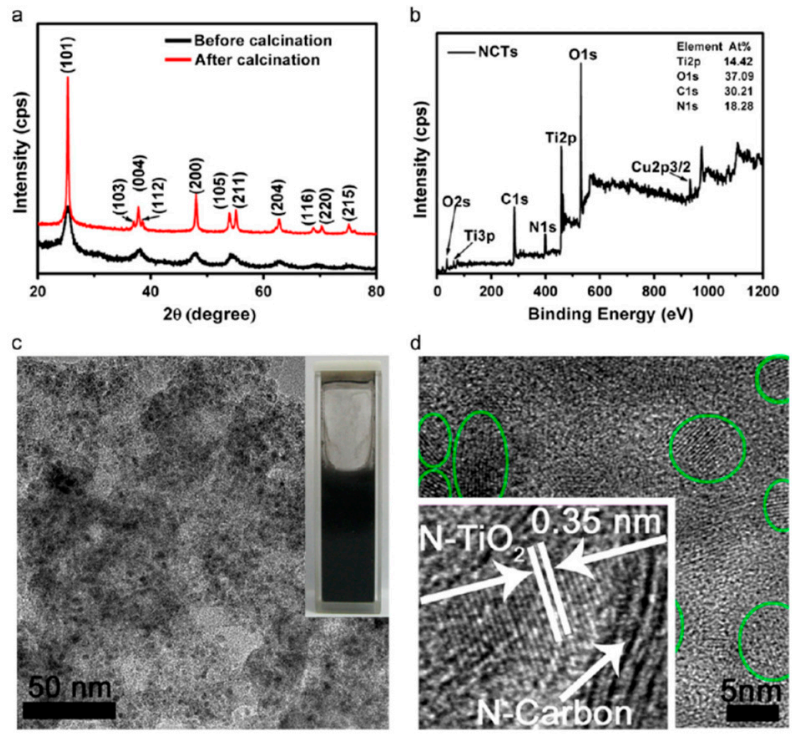

Figure 5. (a) XRD patterns and (b) XPS full spectrum of $\mathrm{N}$-doping carbon- $\mathrm{TiO}_{2}$ nanohybrids. (c) TEM image. Inset: digital image of $\mathrm{N}$-doping carbon- $\mathrm{TiO}_{2}$ nanohybrids solution. (d) HR-TEM image. Inset: HR-TEM image of single $\mathrm{N}-\mathrm{TiO}_{2}$ on $\mathrm{N}$ doped $\mathrm{C}$ film (N-Carbon). From Ref. [58]. Reprinted with permission from Elsevier.
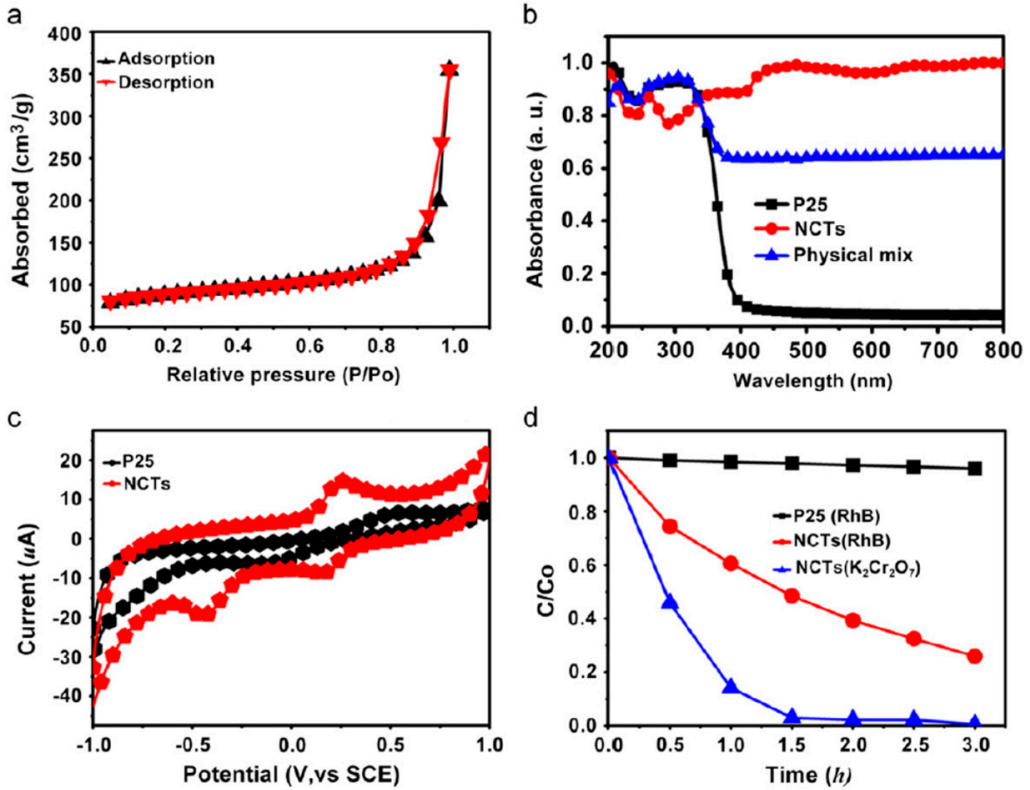

Figure 6. (a) $\mathrm{N}_{2}$ adsorption-desorption isotherm of $\mathrm{N}$-doping carbon- $\mathrm{TiO}_{2}$; (b) UV-VIS diffuse reflectance absorption spectra of $\mathrm{P} 25, \mathrm{~N}$-doping carbon- $\mathrm{TiO}_{2}$ and physical mix; (c) CV spectra of P25 and N-doping carbon- $\mathrm{TiO}_{2}$; (d) Photodegradation of rhodamine $\mathrm{B}(\mathrm{RhB})$ and $\mathrm{K}_{2} \mathrm{Cr}_{2} \mathrm{O}_{7}$ over P25 and $\mathrm{N}$-doping carbon- $\mathrm{TiO}_{2}$. From Ref. [58]. Reprinted with permission from Elsevier.

Using polystyrene spheres as templates and polyaniline as both $\mathrm{C}$ and $\mathrm{N}$ doping sources, mesoporous $\mathrm{C}$ and $\mathrm{N}$ co-doped $\mathrm{TiO}_{2}$ hybrid shells were synthesized [59], which exhibited enhanced photocatalytic activity in the degradation of organic dyes and $\mathrm{H}_{2}$ production under visible light irradiation, compared to their undoped counterpart. The co-doped $\mathrm{C}$ and $\mathrm{N}$ and the presence of graphite carbon were reported to be attributed to the enhanced visible light absorption and charge separation efficiency. They authors observed the synergistic effect in photoelectrochemical reactions exemplified by the concurrent oxidization of perfluorooctanoic acid and hydrogen generation over C-N co-doped $\mathrm{TiO}_{2}$ nanotube arrays as a photoanode [60]. 
By a thermal treatment of titanium substrates embedded in aluminosilicates or alumina particles, $\mathrm{C}-\mathrm{N}$ co-doped $\mathrm{TiO}_{2}$ thin film photoanodes were prepared at $500{ }^{\circ} \mathrm{C}$ for three hours [61]. The as-prepared $\mathrm{C}-\mathrm{N}$ co-doped $\mathrm{TiO}_{2}$ photoanodes showed a significant water oxidation with the high photo currents of about $100 \mathrm{mu} \mathrm{A} \mathrm{cm}{ }^{-2}$ at zero bias when using alumina as the reactant medium under a standard one SUN illumination of a solar simulator. This photoanode showed a stable photocurrent for about $10 \mathrm{~h}$ in the long-term stability test, strong absorption to the visible light region, and improved electron donor density. An in situ carbonization method was also reported to prepare worm-like $\mathrm{C}-\mathrm{N}$ co-doped $\mathrm{TiO}_{2}$ nanocrystallites with high surface areas for efficient photocatalysis using tetrakis (dimethylamino) titanium as both titanium oxide and nitrogen-dopant sources, and the mesoporous carbon molecular sieves CMK-3 as a hard template as well as carbon doping source [62]. The carbon and nitrogen elements were proven to be responsible for the enhanced visible light-driven photocatalytic activity.

\subsection{Photocatalysts of Metal-C Doped $\mathrm{TiO}_{2}$ Composites}

Metal-C doped $\mathrm{TiO}_{2}$ composites were reported to improve their photocatalytic activity due to the coupling effect of the incorporation of carbon species and metal nanoparticles. The eggshell membrane templating method was developed to synthesize porous organic carbon-doped titania $\left(\mathrm{C}-\mathrm{TiO}_{2}\right)$ nanomaterials and their composites with $\mathrm{Ag}$ nanoparticles $\left(\mathrm{Ag} / \mathrm{C}-\mathrm{TiO}_{2}\right)$ [63]. The doped organic carbon was composed of the active carbon and carbonate species, forming a layer around the surface of $\mathrm{TiO}_{2}$ nanoparticles. In the degradation of methylene blue under visible light irradiation, both $\mathrm{C}-\mathrm{TiO}_{2}$ and $\mathrm{Ag} / \mathrm{C}-\mathrm{TiO}_{2}$ nanomaterials showed higher photocatalytic activity compared with the pure $\mathrm{TiO}_{2}$ material, commercial Degussa P25. These results can be assigned to the coupling effect of the incorporation of carbon species and $\mathrm{Ag}$ nanoparticles. $\mathrm{Ag} / \mathrm{C}-\mathrm{TiO}_{2}$ nanomaterials were also prepared by a one-step synthetic approach through the thermal oxidation of an $\mathrm{AgNO}_{3}$-impregnated $\mathrm{TiC}$ precursor [64]. The loaded silver nanoparticles were uniformly distributed on the $\mathrm{TiO}_{2}$ surface in the $\mathrm{Ag}^{0}$ metallic state, further enhancing the visible light absorption due to the surface plasmon resonance, yet inhibiting the charge carrier recombination by conduction band electron trapping. The authors proposed the band structure and a tentative visible light photocatalytic disinfection mechanism of $\mathrm{Ag} / \mathrm{C}-\mathrm{TiO}_{2}$ with four pathways. They demonstrated the enhanced visible light photocatalytic performance for the disinfection of $\mathrm{E}$. coli and $\mathrm{E}$. fecalis in comparison with $\mathrm{C}-\mathrm{TiO}_{2}$.

$\mathrm{Mo} / \mathrm{C}$ co-doped $\mathrm{TiO}_{2}$ powders were reported by thermal oxidizing a mixture of $\mathrm{TiC}$ and $\mathrm{MoO}_{3}$ powders in the air [65]. A 32-nm red shift of the spectrum in the visible absorption onset for these materials was observed. $\mathrm{Mo} / \mathrm{C}$ co-doped $\mathrm{TiO}_{2}$ displayed enhanced photocatalytic activity in the decomposition of methylene blue, and the photocurrent was about four times as high as that of pure anatase $\mathrm{TiO}_{2}$. A calcination-assisted solvothermal reaction was used to prepare the $\mathrm{Nd}$ and $\mathrm{C}$ co-doped $\mathrm{TiO}_{2}\left(\mathrm{Nd}-\mathrm{C}-\mathrm{TiO}_{2}\right)$ without the addition of any other $\mathrm{C}$ precursors [66]. The as-prepared sample had a dramatically improved visible absorption, covering the UV and whole visible light range from 200 to $900 \mathrm{~nm}$. Nd-C- $\mathrm{TiO}_{2}$ was reported to represent the excellent destruction ability of NOx gas and degradation activity of methyl orange solution under visible light irradiation, which was superior to pure $\mathrm{TiO}_{2}, \mathrm{C}-\mathrm{TiO}_{2}$, and $\mathrm{Nd}-\mathrm{TiO}_{2}$.

A hydrothermal approach was reported to synthesize $\mathrm{C}-\mathrm{Fe}$ co-doped $\mathrm{TiO}_{2}$ sheets with dominant $\{001\}$ facets using $\mathrm{TiC}$ and $\mathrm{Fe}_{2} \mathrm{O}_{3}$ as the reactants in an $\mathrm{HNO}_{3}-\mathrm{HF}$ mixed solution [67], resulting in the aggregates of highly truncated bipyramidal microsheets with the length of one to two $\mu \mathrm{m}$ and the thickness of 100-200 nm (Figure 7). The incorporation of Fe into anatase $\mathrm{TiO}_{2}$ did not affect the growth of $\mathrm{TiO}_{2}$ microsheets. The corresponding SAED pattern demonstrated the flat and square surface belonging to the (001) plane of anatase $\mathrm{TiO}_{2}$ (Figure 7a). One can find the (020) and (200) atomic planes with a lattice spacing of $0.19 \mathrm{~nm}$ and a vertical angle (Figure $7 \mathrm{~b}$ ). These composites exhibited the narrow band gap, strong visible light absorption, and high separation efficiency of photogenerated carriers, compared with the $\mathrm{C}$-doped $\mathrm{TiO}_{2}$ sheets. The authors suggested that these 
materials might become promising visible light photocatalysts for organic pollutant degradation and efficient $\mathrm{H}_{2}$ evolution.
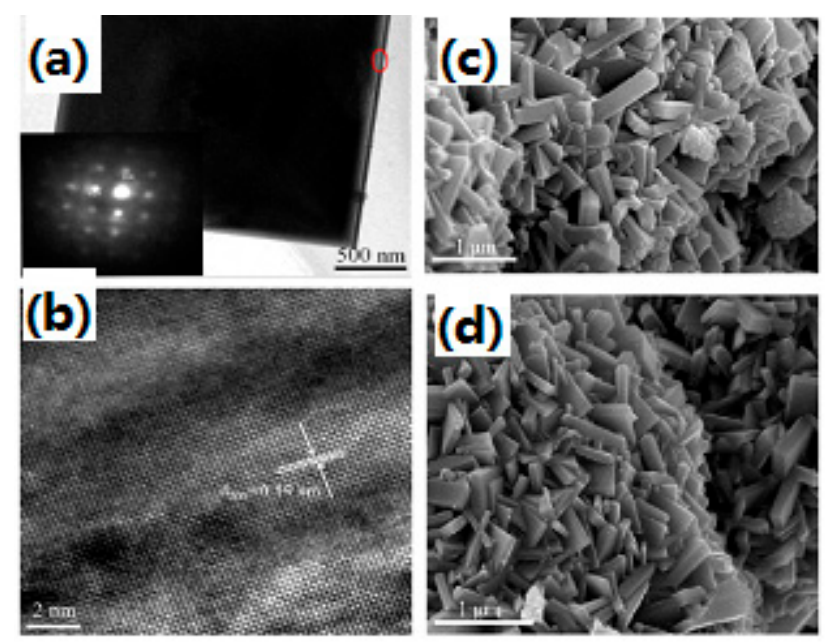

Figure 7. TEM image (a), HR-TEM image (b), and SEM image (c,d) of CFTS-1.0. The inset in Figure 6a is the selected area electron diffraction pattern. From Ref. [67]. Reprinted with permission from ACS.

The synergistic effect of $\mathrm{C}-\mathrm{Ag}$ co-doped $\mathrm{TiO}_{2}$ photocatalysts was observed within the GGA plus $\mathrm{U}$ framework [68]. C and Ag co-doping could induce a synergistic effect, compared with single $\mathrm{C}$ and single Ag doping. After co-doping, the visible absorption was stronger for both the near and far distance co-doped systems than those of the single-doped systems. First-principle calculation was applied to estimate all the band structures, density of states, and absorption spectra of pure, Nd-doped, C-doped, and $\mathrm{Nd}-\mathrm{C}$ co-doped $\mathrm{TiO}_{2}$ based on the density functional theory [69]. Recently, $\mathrm{Ag}$ and $\mathrm{Cu}$ co-doped $\mathrm{TiO}_{2}$ deposited on polyurethane was synthesized for the conversion of $\mathrm{TiO}_{2}$ into solar fuels under visible light irradiation [70]. The as-synthesized materials exhibited very high photocatalytic activity for the reduction of gaseous $\mathrm{CO}_{2}$ to produce $\mathrm{CH}_{4}$ and $\mathrm{CO}$ fuels. The $\mathrm{Ag}$ and $\mathrm{Cu}$ dopants also enhanced the separation of the electron-hole pairs of the doped $\mathrm{TiO}_{2}$ photocatalysts, exhibiting the highest photocatalytic reduction of $\mathrm{CO}_{2}$. A silver/carbon co-doped titanium dioxide photocatalyst was also fabricated for improving dye degradation under visible light irradiation through the hydrolysis of titanium tetrachloride followed by calcination at $500{ }^{\circ} \mathrm{C}$ [71]. The co-doping of $\mathrm{TiO}_{2}$ with $\mathrm{Ag}$ and carbon resulted in an increase in the surface area of the photocatalyst and altered the ratio of anatase to the rutile phase. In comparison with undoped $\mathrm{TiO}_{2}$, doping $\mathrm{TiO}_{2}$ using carbon showed higher photocatalytic activity toward methyl orange degradation under visible light irradiation.

\subsection{Photocatalysts of Other Co-Doped $\mathrm{C} / \mathrm{TiO}_{2}$ Composites}

The synergetic effect is one of the key factors improving the photocatalytic efficiency of co-doped $\mathrm{C} / \mathrm{TiO}_{2}$ composites. $\mathrm{Xu}$ and Zhang demonstrated the controlled synthesis of $\mathrm{C}-\mathrm{Cl}$ co-doped anatase $\mathrm{TiO}_{2}$ nanocrystals with mesoporous structures and high surface areas between $158.1-469.6 \mathrm{~m}^{2} \mathrm{~g}^{-1}$ by the hydrolysis of titanium tetraisopropoxide in chloroform containing trace amounts of water at a low temperature of $150{ }^{\circ} \mathrm{C}$ without a subsequent thermal procedure [72]. $\mathrm{C}-\mathrm{Cl}$ co-doped anatase $\mathrm{TiO}_{2}$ exhibited higher photoactivity in the photodegradation of $\mathrm{RhB}$ under visible light irradiation, compared with $\mathrm{C}-\mathrm{TiO}_{2}$ and $\mathrm{Cl}-\mathrm{TiO}_{2}$, which was attributed to the larger surface area and the synergetic effect of the co-doping. Hierarchically meso/nanoporous $\mathrm{S}$ and $\mathrm{C}$ co-doping $\mathrm{TiO}_{2}$ was fabricated by a hydrolysis and calcination method using $\mathrm{Ti}\left(\mathrm{OC}_{4} \mathrm{H}_{9}\right)_{4}$ and $\mathrm{K}_{2} \mathrm{~S}_{2} \mathrm{O}_{8}$ as precursors [73]. The $\mathrm{S}$ and $\mathrm{C}$ co-doped $\mathrm{TiO}_{2}$ was found to exhibit high photocatalytic $\mathrm{H}_{2}$ generation efficiency in a water/methanol sacrificial reagent system under the irradiation of UV light. Experimental results indicated that the high photocatalytic efficiency is dependent on the comprehensively competing effects of the co-doping of $S$ and $C$, crystallization, specific surface area, and light absorption capability. 
The synthesis of $\mathrm{S}$ and $\mathrm{C}$ co-doped hierarchically meso/nanoporous $\mathrm{TiO}_{2}$ with excellent thermal stability and photocatalytic activity was reported by $\mathrm{Xu}$ et al. [74]. The sulfur nanoparticles in the sulfur hydrosol were applied to serve as the seeds for the formation of bimodal meso/nanopores $\mathrm{TiO}_{2}$ upon calcination treatment. The authors observed remarkably enhanced photocatalytic activity and excellent cyclic stability on the decomposition of methylene blue in the visible light region, which was attributed to the numerous oxygen vacancies, acidic sites on the surface of $\mathrm{TiO}_{2}$, and large specific surface area. The sol-gel method combining with high-energy ball milling was employed to synthesize the $(\mathrm{N}, \mathrm{S}$, and $\mathrm{C})$ co-doped $\mathrm{TiO}_{2}$ calcined at the different temperatures $\left(400-700{ }^{\circ} \mathrm{C}\right)$, employing butyl titanate as the titanium source and thiourea as the doping agent [75]. The (N, S, and C) co-doping and the calcination temperature played an important role in the microstructure and photocatalytic activity of the samples, judging from the photocatalytic reduction of $\mathrm{Cr}(\mathrm{VI})$ as a model compound under visible light irradiation. As for the control of $\mathrm{TiO}_{2-500}$, it did not cause the concentration decrease of $\mathrm{Cr}(\mathrm{VI})$ in aqueous solution upon visible light irradiation for 50 minutes (Figure 8a). In the presence of $\left(\mathrm{N}, \mathrm{S}\right.$, and $\mathrm{C}$ ) co-doped $\mathrm{TiO}_{2-\mathrm{x}}$ samples, a quick concentration decrease of $\mathrm{Cr}(\mathrm{VI})$ was observed. Moreover, the concentration of $\mathrm{Cr}(\mathrm{VI})$ decreased quickly with the increase of calcination temperature from $500{ }^{\circ} \mathrm{C}$ to $700{ }^{\circ} \mathrm{C}$. It was found that the decrease in the visible absorption, the separation rate of the electron-hole pairs, the specific surface area, and the increase in crystal size for $(\mathrm{N}, \mathrm{S}$, and $\mathrm{C}$ ) co-doped $\mathrm{TiO}_{2-\mathrm{x}}$ samples resulted in the decrease in photocatalytic performance (Figure $8 \mathrm{~b}$ ).
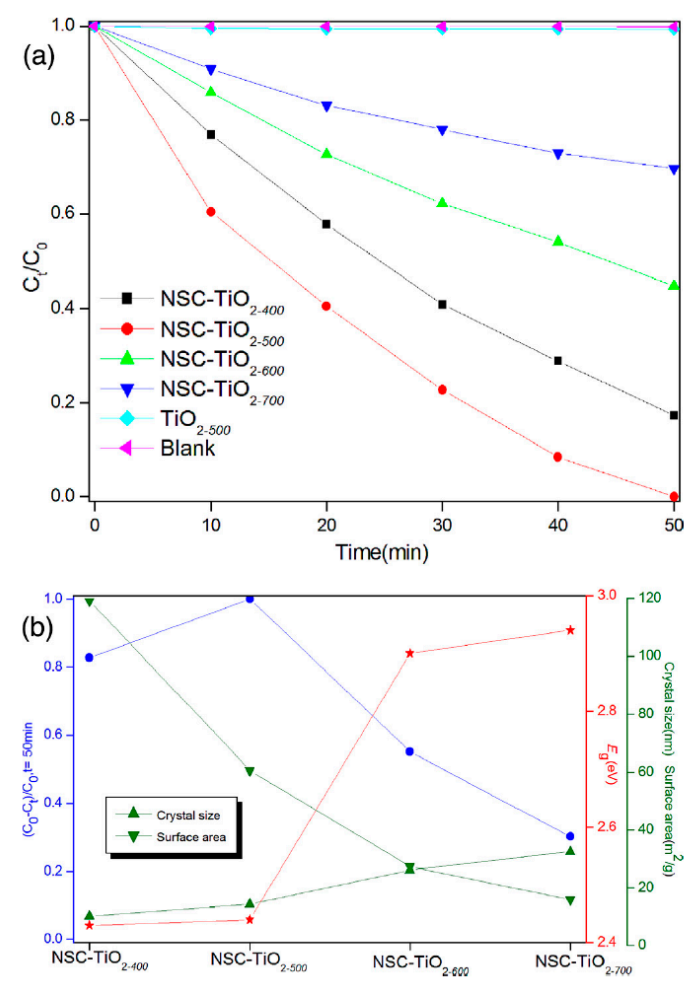

Figure 8. (a) Variation of $\mathrm{Cr}(\mathrm{VI})$ concentration ( $\mathrm{pH} 1.5$ and $\mathrm{C} 0=10 \mathrm{mg} / \mathrm{L}$ ) with irradiation time in the presence of $\mathrm{TiO}_{2-500}$ and $(\mathrm{N}, \mathrm{S}$, and $\mathrm{C})$ co-doped $\mathrm{TiO}_{2-x}$ samples under visible light $(\lambda>420 \mathrm{~nm})$ irradiation, together with the results from the blank experiments (no photocatalyst, but with visible light irradiation); (b) plots of $\left[\left(C_{0}-C_{t}\right) / C_{0}, t=50 \mathrm{~min}\right]$ in comparison with $E g$ values, specific surface area, and crystal size for all (N, S, and C) co-doped- $\mathrm{TiO}_{2-x}$ samples. From Ref. [75]. Reprinted with permission from Elsevier.

\section{Photocatalysts of $\mathrm{C} / \mathrm{g}-\mathrm{C}_{3} \mathrm{~N}_{4}$ Composites}

Graphitic carbon nitride $\left(\mathrm{g}-\mathrm{C}_{3} \mathrm{~N}_{4}\right)$ is a research hotspot material as a promising photocatalyst due to its good photocatalytic performance and unique electronic structure. A sonochemical method was applied to fabricate the mesoporous g- $\mathrm{C}_{3} \mathrm{~N}_{4}$ /graphene and mesoporous g- $\mathrm{C}_{3} \mathrm{~N}_{4}$ / graphene oxide 
nanocomposites with high visible light photocatalytic activity (NO removal ratios of $64.9 \%$ and $60.7 \%$, respectively) [76]. The authors suggested that this photocatalytic performance could be attributed to the high surface area and pore volume, improved visible light utilization, enhanced reduction power of electrons, and promoted separation of charge carriers. In Shi's work, a thermal treatment was also developed during the preparation of the ordered mesoporous carbon/g- $\mathrm{C}_{3} \mathrm{~N}_{4}$ composites with efficient photocatalytic activity under visible light irradiation [77], which exhibited very high photocatalytic activities in degrading RhB dye, and the high degradation rate was almost 10 times that of pristine g- $\mathrm{C}_{3} \mathrm{~N}_{4}$, which was partly due to the ordered mesoporous carbon. After five cycles, these composites retained good stability and photodegradation efficiency. The authors suggested that the combined effects came from the enhanced visible light absorption, enriched the dye adsorption on the catalyst, and subsequent efficient separation of the photogenerated electrons and holes. Recently, an in situ synthesis of C-doped $\mathrm{TiO}_{2} @ g-\mathrm{C}_{3} \mathrm{~N}_{4}$ core-shell hollow nanospheres with remarkably enhanced visible light photocatalytic activity for water splitting to produce $\mathrm{H}_{2}$ were reported [78], exhibiting the $\mathrm{H} 2$ generation rate of $35.6 \mathrm{mu} \mathrm{mol} \mathrm{g} \mathrm{h}^{-1}$. The heterojunction, in situ growth, and unique hollow structure favored the enhanced photocatalytic performance.

Hydrothermal treatment was also applied to synthesize the $\mathrm{C} / \mathrm{g}-\mathrm{C}_{3} \mathrm{~N}_{4}$ composites with a mixture of $g-C_{3} N_{4}$ and glucose solution [79]. The authors discovered that carbon doping by glucose is an efficient way to improve the photocatalytic performance of $\mathrm{g}_{-} \mathrm{C}_{3} \mathrm{~N}_{4}$ due to the synergistic effect between carbon and $\mathrm{g}-\mathrm{C}_{3} \mathrm{~N}_{4}$, leading to increased visible light absorption, enhanced absorptivity, and improved photoinduced electron-hole separation efficiency. A $97 \%$ degradation of Methylene blue (MB) by $\mathrm{C} 2 / \mathrm{g}-\mathrm{C}_{3} \mathrm{~N}_{4}$ composite was observed within 2.0 hours under visible light irradiation, while the pure g- $\mathrm{C}_{3} \mathrm{~N}_{4}$ only caused a $73 \%$ degradation of $\mathrm{MB}$ (Figure 9). The photocatalytic activity of $\mathrm{C} / \mathrm{g}-\mathrm{C}_{3} \mathrm{~N}_{4}$ composites increased with the weight of the glucose precursor from $0.0025 \mathrm{~g}$ to $0.005 \mathrm{~g}$. By adding a small amount of citric acid into urea as the precursor, $\mathrm{N}$-doped graphitic carbon-incorporated g- $\mathrm{C}_{3} \mathrm{~N}_{4}$ could be synthesized during thermal polymerization [80]. The as-obtained materials retained the original framework of $\mathrm{g}-\mathrm{C}_{3} \mathrm{~N}_{4}$, and showed remarkably enhanced visible light harvesting, and promoted photoexcited charge carrier separation and transfer. They demonstrated an $\mathrm{H}_{2}$ evolution rate of $64 \mathrm{mu} \mathrm{mol} \mathrm{h}{ }^{-1}$ on $\mathrm{N}$-doped graphitic carbon-incorporated g- $\mathrm{C}_{3} \mathrm{~N}_{4}$ under visible light irradiation. This polymerized method was also employed to obtain the visible light-driven $\mathrm{N}$-doped carbon dots $/ \mathrm{g}-\mathrm{C}_{3} \mathrm{~N}_{4}$ photocatalyst composite with enhanced visible light photocatalytic activity for the degradation of indomethacin [81]. This enhanced photocatalytic activity might be ascribed to the unique up-converted Photoluminescence (PL) properties, efficient charge separation, as well as band gap narrowing of the $\mathrm{N}$-doped carbon dots. The authors indicated that this composite possesses a very desirable performance for the toxicity reduction and mineralization of indomethacin under long exposures of visible light irradiation.

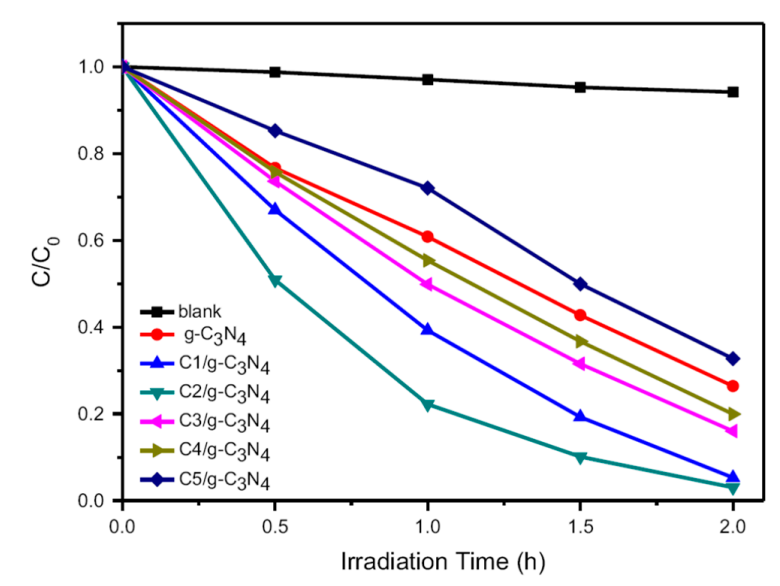

Figure 9. Photocatalytic degradation efficiency of Methylene blue (MB) by graphitic carbon nitride $\left(\mathrm{g}-\mathrm{C}_{3} \mathrm{~N}_{4}\right)$ and $\mathrm{C} / \mathrm{g}-\mathrm{C}_{3} \mathrm{~N}_{4}$ composites. From Ref. [79]. Reprinted with permission from Elsevier. 
The precipitation method was introduced to fabricate robust $\mathrm{g}-\mathrm{C}_{3} \mathrm{~N}_{4}$ nanosheets/carbons/NiS multiple heterojunctions for photocatalytic $\mathrm{H}_{2}$ generation [82]. In this work, the authors used the nanocarbons as effective $\mathrm{H}_{2}$-evolution co-catalysts and conductive electron bridges to collect photogenerated electrons, resulting in the downshift of the valence band of $g-C_{3} N_{4}$ and facilitating the fast oxidation of triethanolamine and charge carrier separation. They also discovered that the amorphous carbons with high electrical conductivity and weak electrocatalytic $\mathrm{H}_{2}$-evolution activity are suitable interfacial bridges between $\mathrm{g}-\mathrm{C}_{3} \mathrm{~N}_{4}$ and $\mathrm{NiS}$ co-catalysts for maximizing $\mathrm{H}_{2}$ generation. More recently, a thermal treatment method was employed to synthesize a metal organic framework-derived, nitrogen-doped, carbon-modified g- $\mathrm{C}_{3} \mathrm{~N}_{4}$ heterostructure composite with enhanced photocatalytic activity for bisphenol A degradation with peroxymonosulfate under visible light irradiation [83], which had the hierarchical porosity, conductive network, and abundant exposed active sites for peroxymonosulfate activation. In this research, the as-prepared heterostructure composite exhibited remarkably improved photocatalytic activities toward bisphenol A degradation in the presence of peroxymonosulfate under visible light irradiation, displaying approximately 8.6 times the apparent rate constant of bare $\mathrm{g}-\mathrm{C}_{3} \mathrm{~N}_{4}$. In general, all these examples mentioned above demonstrated that the carbon doping is an efficient strategy to improve the photocatalytic property of g- $\mathrm{C}_{3} \mathrm{~N}_{4}$ and that a synergistic effect exists between carbon and $\mathrm{g}-\mathrm{C}_{3} \mathrm{~N}_{4}$.

\section{Photocatalysts of Ternary C-Doped Composites}

Similar to metal C-doped $\mathrm{TiO}_{2}$ composites, ternary C-doped composites also displayed the synergistic effect from the ternary interfaces. Shen et al. synthesized the magnetic $\mathrm{Fe}_{3} \mathrm{O}_{4} @ \mathrm{C}$ $@ \mathrm{Cu}_{2} \mathrm{O}$ composites with a bean-like core/shell nanostructure by a self-assembly approach [84]. They obtained as-prepared magnetic composites with a size of about $420 \mathrm{~nm}$ and shells that were composed of several nanoparticles in the range of five to $10 \mathrm{~nm}$. The carbonaceous layer with bound hydrophilic groups was reported to inherit from the starting materials, acting as both the linker and the stabilizer between $\mathrm{Fe}_{3} \mathrm{O}_{4}$ and $\mathrm{Cu}_{2} \mathrm{O}$. The $\mathrm{Fe}_{3} \mathrm{O}_{4} @ \mathrm{C} @ \mathrm{Cu}_{2} \mathrm{O}$ composites were found to exhibit ferromagnetic behavior, good dispersibility in aqueous solution, and universal and powerful visible light photocatalytic activity for the degradation of $\mathrm{RhB}$, methyl orange (MO), and alizarin red (AR), which was superior to commercial $\mathrm{Cu}_{2} \mathrm{O}$ and Degussa P-25 powders. They suggested that these novel magnetic composites might have applications in dye solution treatment, the degradation of organic pollutants, and environmental cleaning.

The multi-step process of hydrothermal reaction and microwave irradiation was used to synthesize one-dimensional coaxial nanostructures composed of $\mathrm{ZnO}$ nanorod cores, intermediate amorphous carbonaceous layers, and CdS nanoparticle sheaths (i.e. $\mathrm{ZnO} / \mathrm{C} / \mathrm{CdS}$ nanocables) [85]. A single coaxial $\mathrm{ZnO} / \mathrm{C} / \mathrm{CdS}$ nanocable was obtained, in which $\mathrm{ZnO}$ nanoparticles were encapsulated by an amorphous carbonaceous layer with the thickness of about five $\mathrm{nm}$, and $\mathrm{CdS}$ nanoparticles with the size of about $5.5 \mathrm{~nm}$ were uniformly deposited on the surface of the carbon layer. In addition, the thickness of the amorphous carbonaceous layer was reported to be easily tuned from three to $10 \mathrm{~nm}$ by controlling the amount of glucose from 0.1 to $0.3 \mathrm{~g}$. As for the high concentration of $\mathrm{Cd}^{2+}$, more CdS nanoparticles were anchored onto the amorphous carbonaceous layer, and the size of the $\mathrm{CdS}$ nanoparticles became larger with the increasing of the $\mathrm{Cd}^{2+}$ concentration. The thickness of the carbonaceous layer and the amount of CdS nanoparticles can be tuned by controlling the glucose intake and the cadmium salt concentration, respectively. The as-prepared $\mathrm{ZnO} / \mathrm{C} / \mathrm{CdS}$ nanocables exhibited much higher activity than that of pure $\mathrm{ZnO}$ nanorods, pure $\mathrm{CdS}$, and $\mathrm{ZnO} / \mathrm{C}$ core-shell nanocables for the degradation of RhB and methylene blue (MB) under visible light irradiation, which was due to stronger adsorption and the synergistic effect from the ternary $\mathrm{ZnO} / \mathrm{C} / \mathrm{CdS}$ interface.

In the previous literature, $\mathrm{Li}$ et al. also found the synergistic effect in sandwiched $\mathrm{TiO}_{2} @ \mathrm{Au} @ \mathrm{C}$ hollow spheres. The hydrothermal reaction and calcination were applied to the fabrication of uniform double-shelled and sandwiched $\mathrm{TiO}_{2} @ \mathrm{Au} @ \mathrm{C}$ hollow and porous spheres [86]. An HR-TEM image of the nanocomposite showed the (101) crystallographic planes of $\mathrm{TiO}_{2}$, the (111) plane of $\mathrm{Au}$ 
nanoparticles, and the coated carbon layer with a thickness of ca. $10 \mathrm{~nm}$ in Figure 10b,c displayed the presence of individual nanoparticles on a thick and layered shell. It was found that these microspheres displayed high photocatalytic activity and photocatalytic stability for the degradation of 4-nitroaniline, and the remarkable photocatalytic activity for hydrogen generation from methanol/water solutions. $\mathrm{TiO}_{2} @ \mathrm{Au} @ \mathrm{C}$ achieved a visible light photodegradation of $92.65 \%$ for 4-nitroaniline, while P25 only displayed a visible light photodegradation of $17.61 \%$ of 4 -nitroaniline (Figure 11). It was also observed that the photodegradation reactions followed a pseudo-first-order kinetics with the rate constants $\left(0.0012 \mathrm{~min}^{-1}, 0.0004 \mathrm{~min}^{-1}, 0.0050 \mathrm{~min}^{-1}, 0.0046 \mathrm{~min}^{-1}\right.$, and $\left.0.015 \mathrm{~min}^{-1}\right)$ for 4-nitroaniline and the rate constants $\left(0.0009 \mathrm{~min}^{-1}, 0.0014 \mathrm{~min}^{-1}, 0.0036 \mathrm{~min}^{-1}, 0.0033 \mathrm{~min}^{-1}\right.$, and $\left.0.081 \mathrm{~min}^{-1}\right)$ for 4-nitrophenol by P25, hollow $\mathrm{TiO}_{2}$, hollow $\mathrm{TiO}_{2} @ \mathrm{C}$, hollow $\mathrm{TiO}_{2} / \mathrm{Au}$, and double-shelled and sandwiched $\mathrm{TiO}_{2} @ \mathrm{Au} @ \mathrm{C}$ hollow spheres, respectively, under visible light irradiation. They proposed the synergistic effect of coupling $\mathrm{TiO}_{2}$ hollow spheres with $\mathrm{Au}$ nanoparticles and a $\mathrm{C}$ shell in photocatalytic performance.

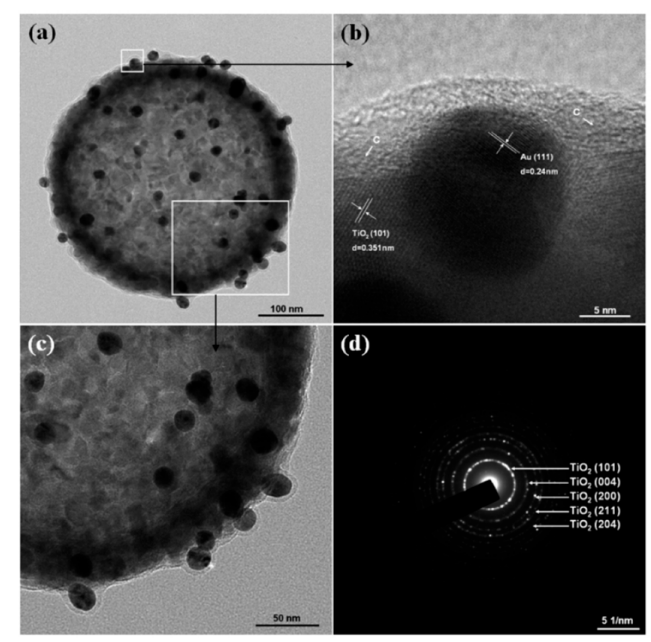

Figure 10. TEM $(\mathbf{a}, \mathbf{c})$, HR-TEM $(\mathbf{b})$, and SAED $(\mathbf{d})$ images of double-shelled and sandwiched $\mathrm{TiO}_{2} @ \mathrm{Au} @ \mathrm{C}$ hollow spheres. From Ref. [86]. Reprinted with permission from ACS.
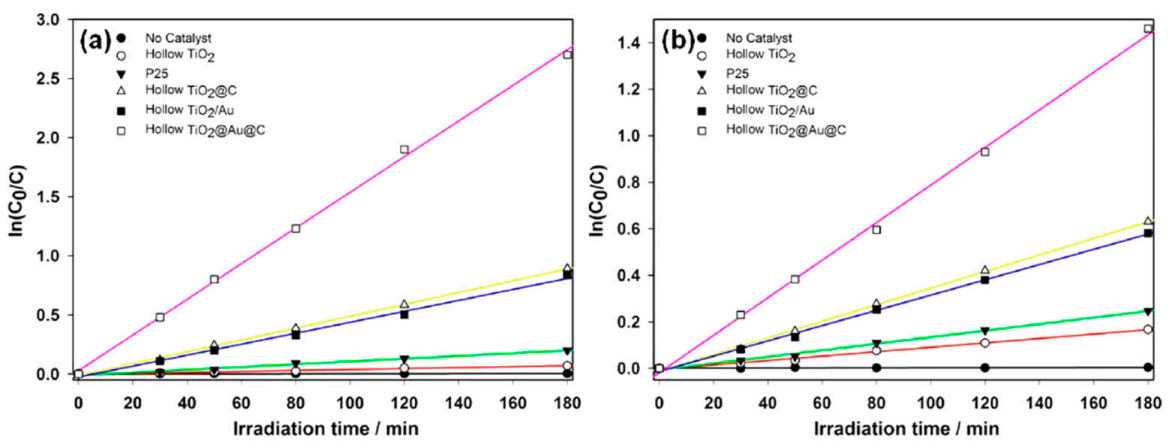

Figure 11. Linear transform $\ln \left(\mathrm{C}_{0} / \mathrm{C}\right)=\mathrm{f}(\mathrm{t})$ of the kinetic curves of (a) 4-nitroaniline or (b) 4-nitrophenol photodegradation by $\mathrm{P} 25$, hollow $\mathrm{TiO}_{2}$, hollow $\mathrm{TiO}_{2} @ \mathrm{C}$, hollow $\mathrm{TiO}_{2} / \mathrm{Au}$, and double-shelled and sandwiched $\mathrm{TiO}_{2} @ \mathrm{Au} @ \mathrm{C}$ hollow spheres under visible light irradiation. From Ref. [86]. Reprinted with permission from ACS.

\section{Photocatalysts of Other C-doped Composites}

The semiconductor $\mathrm{ZnO}$ has been attracting considerable attention because of its large exciton binding energy $(60 \mathrm{meV})$ and possible applications to UV light emitters, gas sensors, transparent electronics, photocatalysis, solar cell, environmental remediation, and surface acoustic wave devices. Novel ZnO@C hybrid composites were obtained using a metal organic framework as a precursor [87]. The resultant $\mathrm{ZnO}$ hierarchical aggregates with a three-dimensional cubic morphology and $\mathrm{ZnO@C}$ 
hybrid composites within a highly porous carbonaceous species were obtained. The hybrid composites showed relatively high photocatalytic decomposition activity and significantly enhanced adsorption capacities for organic pollutants. The hydrothermal method was reported for the synthesis of ZnO@C coaxial gemel hexagonal microrods with a thin carbon layer on their surface by using furfural as the carbon precursor, and they showed high photocatalytic activity and stability [88]. The thickness of the surface carbon layer was found to increase with the hydrothermal time until $16 \mathrm{~h}$. The carbon layer was reported to play a significantly important role in the photocatalytic activities and photostabilities of the ZnO@C microrods for the UV-irradiated photodegradation of methylene blue solution. Zhou et al. described the deposition of carbon on the surface of $\mathrm{ZnO}$ nanoparticles via an adsorption and calcination process [89]. The as-prepared $\mathrm{ZnO} / \mathrm{C}$ exhibited much higher photocatalytic properties and adsorption capacity for $\mathrm{MB}$, compared with pure $\mathrm{ZnO}$ and carbon, because of the formation of heteroarchitectures, which was tested by photocatalytic decomposition and adsorption of the dye methylene blue in aqueous solution. $\mathrm{ZnO} / \mathrm{C}$ showed a pseudo-first-order rate constant of $0.326 \mathrm{~min}^{-1}$, which was 10 times larger than that of pure $\mathrm{ZnO}$.

By combining the electrospinning technique and thermal decomposition process, C-doped $\mathrm{ZnO}$ nanofibers with high visible light photocatalytic activity were fabricated using the precursor solution consisting of polyacrylonitrile and zinc acetate [90]. The C-doped $\mathrm{ZnO}$ nanofibers possessed a much higher photocatalytic degradation rate of $\mathrm{RhB}$ compared with the pure $\mathrm{ZnO}$ nanofibers under visible light irradiation, which was attributed to the formation of the new energy states in $\mathrm{ZnO}$ because of the carbon doping, which might reduce the band gap of the $\mathrm{ZnO}$. By the solvothermal treatment of zinc acetate in an ethylene glycol-ethanol mixture, C-doped $\mathrm{ZnO}$ ball-in-ball hollow microspheres were fabricated for photocatalytic and photoelectrochemical applications [91]. The C-doped $\mathrm{ZnO}$ ball-in-ball hollow microspheres displayed higher photocatalytic active than $\mathrm{ZnO}$ particles by the photodegradation of phenol and MO (Figure 12a). The hollow microspheres exhibited ca. 8.9-fold and 10.5-fold higher activity in comparison with pristine $\mathrm{ZnO}$ nanoparticles as the photocatalyst for organic pollutant degradation and as a photoanode material for photoelectrochemical water splitting, respectively (Figure 12a). The $\mathrm{C}$-doped $\mathrm{ZnO}$ hollow microspheres also showed stable performance in recycling reactions (Figure 12b). As for the photocurrent-voltage (I-V) curves, C-doped ZnO displayed an obviously high photocurrent (Figure 12c), and an about 10.5 times higher transient photocurrent than $\mathrm{ZnO}$ nanoparticles (Figure 12d).
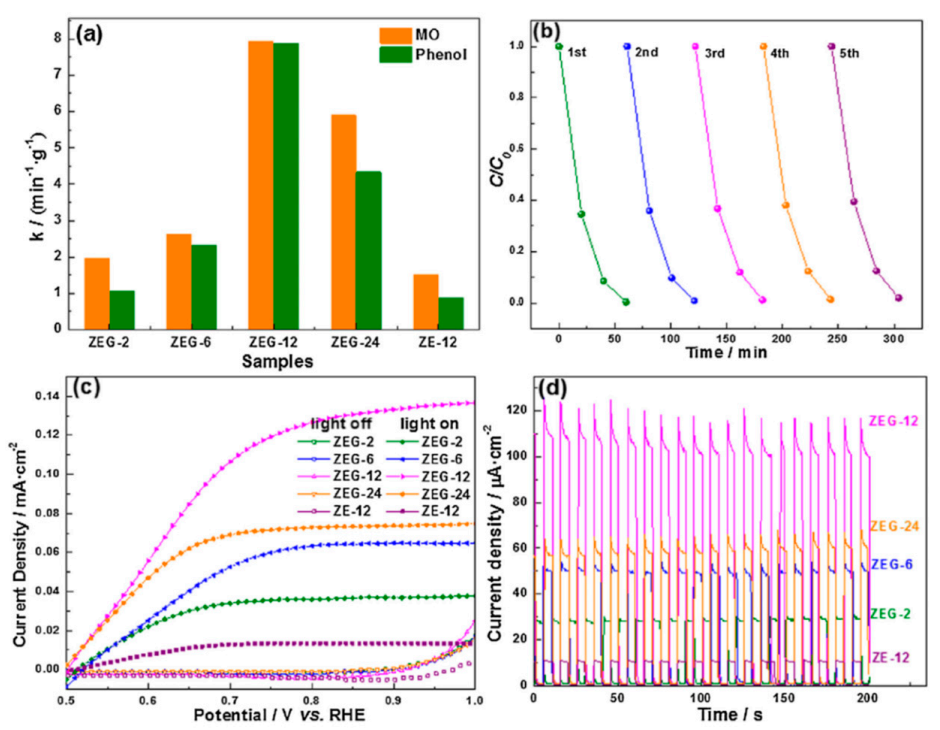

Figure 12. (a) The reaction rate for methyl orange (MO) and phenol photodegradation under UV-VIS irradiation; (b) the recycling of MO photodegradation using ZEG-12; (c) photocurrent-voltage (I-V) curves of $\mathrm{ZnO}$ in dark and under irradiation; (d) transient photocurrent (I-t plots) at $0.85 \mathrm{~V}$ vs. RHE. From Ref. [91]. Reprinted with permission from Elsevier. 
The two-step hydrothermal method was reported to prepare $\mathrm{Bi}_{2} \mathrm{WO}_{6}$-coated carbon microspheres using glucose as a carbon source [92]. By the photocatalytic degradation of gas-phase benzene under visible light irradiation, it was revealed that the photocatalytic performance of the $\mathrm{Bi}_{2} \mathrm{WO}_{6}$ was greatly enhanced by the introduction of carbon microspheres. The $\mathrm{Bi}_{2} \mathrm{WO}_{6} @ \mathrm{C}$ microspheres displayed a photocatalytic benzene conversion of $42.6 \%$ and benzene mineralization of $80.0 \%$, respectively. As a direct wide band-gap semiconductor, $\mathrm{ZnS}$ nanostructure displayed unique properties, including excellent electrical transport properties, good thermal stability, and high electronic mobility. The density functional theory calculations were used to investigate the origin of the experimentally observed changes in the visible light responsive photoactivity of hexagonal wurtzite $\mathrm{ZnS}$ induced by $(\mathrm{N}, \mathrm{C})$ co-doping [93]. They performed the accurate comparative analyses of geometric and electronic structures for the different doping models. For the mono $\mathrm{N}$-doped or C-doped $\mathrm{ZnS}$ systems, the substituted doping was found to just induce a slight band gap narrowing (less than $0.2 \mathrm{eV}$ ), while the interstitial doping led to a more significant optical absorption red shift. For the $\mathrm{N}-\mathrm{C}$ co-doped systems, the electron transition from the impurity states in the band gap to the conduction band will induce a large red shift, suggesting visible light absorption. The calculated results of $2 \mathrm{~N}-\mathrm{C}$ co-doped $\mathrm{ZnS}$ indicated that the trimer doping induces a larger red shift of photoelectron transition and passivates the partially occupied states by the charge compensation effect in a donor-acceptor pair. This work provided a solid basis for the rationalization of the experimentally observed red shift of optical absorption in wurtzite $\mathrm{ZnS}$ as a consequence of $(\mathrm{N}, \mathrm{C})$ co-doping. Recently, a hydrothermal method was developed to synthesize well-dispersed carbon-doped $\mathrm{ZnSn}(\mathrm{OH})_{6}$ submicrocube photocatalysts at $433 \mathrm{~K}$ using glucose as the carbon-doping source [94], which exhibited higher photocatalytic performance by the decomposition of methylene blue in aqueous solution under visible light irradiation, compared with pure $\mathrm{ZnSn}(\mathrm{OH})_{6}$.

\section{Conclusions and Future Perspectives}

In this review, we summarized the recent advances on the synthesis, photocatalytic properties, and potential applications of photocatalysts based on carbon-based (nano)composites. According to the results from represented examples, these carbon-based (nano)composite photocatalysts exhibited improved photocatalytic properties compared to their individual components. It is worth noting that the synergistic effect is one of the key factors responsible for their photocatalytic performance. Based on our knowledge, some future research trends and directions can be expected as follows. (1) The exploitation of the precursor sources is important for the properties and applications of carbon-based (nano)composites. Various raw materials should be developed as carbon sources. Obviously, different types of biomass such as wood, grass, and bamboo are promising precursor sources of carbon, to which researchers should pay more attention. (2) There have been many examples indicating that the as-prepared carbon-based (nano)composites exhibited improved photocatalytic activity compared with P25 and their individual components. Then, we need to focus on the practical applications of these carbon-based (nano)composites prepared in labs. From an application point of view, it is not enough to obtain carbon-based (nano)composite photocatalysts with only high photocatalytic activity. We should also consider other factors such as the raw materials, production cost, production cycle, yield, and so on. Photocatalytic activity is a key and important factor, but it is not the only factor. It is also important to develop environmentally friendly methods for the large-scale and industrial-scale production of carbon-based nanocomposite photocatalysts at low cost and with high efficiency. (3) There are many examples mentioning the synergistic effect of the incorporation of carbon species in the carbon-based nanocomposite. This effect still needs to be scrutinized in depth, e.g., by using theoretical modeling and computer simulation. Moreover, the relationships between the preparation, structures, properties, and applications of carbon-based nanocomposites need to be dissected in detail. We believe that more and more rapid progresses will be made in the research of carbon-based nanocomposite photocatalysts, since they have broad potential applications in the environmental treatment and renewable energy fields. 
Acknowledgments: This research was funded by the Fundamental Research Funds for the Central Universities grant number [No. 2017ZY49], Swedish Energy Agency, Swedish Research Council, and Stiftelsen Olle Engkvist Byggmästare.

Conflicts of Interest: The authors declare no conflict of interest.

\section{References}

1. Kudo, A.; Miseki, Y. Heterogeneous photocatalyst materials for water splitting. Chem. Soc. Rev. 2009, 38, 253-278. [CrossRef] [PubMed]

2. Zhang, J.L.; Wu, Y.M.; Xing, M.Y.; Leghari, S.A.K.; Sajjad, S. Development of modified N doped $\mathrm{TiO}_{2}$ photocatalyst with metals, nonmetals and metal oxides. Energy Environ. Sci. 2010, 3, 715-726. [CrossRef]

3. Zhu, J.F.; Zäch, M. Nanostructured materials for photocatalytic hydrogen production. Curr. Opin. Coll. Interface Sci. 2009, 14, 260-269. [CrossRef]

4. Zhu, J.F.; Chakarov, D.; Zäch, M. Chapter 13: Nanostructured Materials for Photolytic Hydrogen Production. In Energy Efficiency and Renewable Energy through Nanotechnology; Zang, L., Ed.; Springer: London, UK, 2011; pp. 441-486. ISBN 978-0-85729-637-5.

5. Park, H.; Park, Y.; Kim, W.; Choi, W. Surface modification of $\mathrm{TiO}_{2}$ photocatalyst for environmental applications. J. Photochem. Photobiol. C-Photochem. Rev. 2013, 15, 1-20. [CrossRef]

6. Lee, K.M.; Lai, C.W.; Ngai, K.S.; Juan, J.C. Recent developments of zinc oxide based photocatalyst in water treatment technology: A review. Water Res. 2016, 88, 428-448. [CrossRef] [PubMed]

7. Zhu, J.F. Photocatalytic hydrogen production. In Encyclopedia of Sustainability Science and Technology; Meyers, R.A., Ed.; Springer: New York, NY, USA, 2012; pp. 7881-7901. ISBN 978-0-387-89469-0.

8. Zhu, J.F. Photocatalysts for hydrogen production. In Advanced Materials for Clean Energy; Xu, Q., Kobayashi, T., Eds.; CRC Press, Taylor \& Francis Group: Boca Raton, FL, USA, 2015; pp. 391-420. ISBN 978-1-4822-0578-7.

9. Kumar, S.G.; Devi, L.G. Review on modified $\mathrm{TiO}_{2}$ photocatalysis under UV/visible light: Selected results and related mechanisms on interfacial charge carrier transfer dynamics. J. Phys. Chem. A 2011, 115, 13211-13241. [CrossRef] [PubMed]

10. Kim, J.; Lee, C.W.; Choi, W. Platinized WO3 as an environmental photocatalyst that generates oh radicals under visible light. Environ. Sci. Technol. 2010, 44, 6849-6854. [CrossRef] [PubMed]

11. Gu, X.Q.; Li, C.Y.; Yuan, S.; Ma, M.G.; Qiang, Y.H.; Zhu, J.F. ZnO based heterojunctions and their application in environmental photocatalysis. Nanotechnology 2016, 27, 402001. [CrossRef]

12. Zhu, C.; Liu, C.G.; Zhou, Y.J.; Fu, Y.J.; Guo, S.J.; Li, H.; Zhao, S.Q.; Huang, H.; Liu, Y.; Kang, Z.H. Carbon dots enhance the stability of CdS for visible-light-driven overall water splitting. Appl. Catal. B-Environ. 2017, 216, 114-121. [CrossRef]

13. Reddy, D.A.; Park, H.; Ma, R.; Kumar, D.P.; Lim, M.; Kim, T.K. Heterostructured $\mathrm{WS}_{2}-\mathrm{MoS}_{2}$ ultrathin nanosheets integrated on CdS nanorods to promote charge separation and migration and improve solar-driven photocatalytic hydrogen evolution. Chemsuschem 2017, 10, 1563-1570. [CrossRef]

14. Li, Y.; Wang, L.L.; Cai, T.; Zhang, S.Q.; Liu, Y.T.; Song, Y.Z.; Dong, X.R.; Hu, L. Glucose-assisted synthesize 1D/2D nearly vertical CdS/ $\mathrm{MoS}_{2}$ heterostructures for efficient photocatalytic hydrogen evolution. Chem. Eng. J. 2017, 321, 366-374. [CrossRef]

15. Cao, S.W.; Low, J.X.; Yu, J.G.; Jaroniec, M. Polymeric photocatalysts based on graphitic carbon nitride. Adv. Mater. 2015, 27, 2150-2176. [CrossRef]

16. Yan, S.C.; Lv, S.B.; Li, Z.S.; Zou, Z.G. Organic-inorganic composite photocatalyst of g- $\mathrm{C}_{3} \mathrm{~N}_{4}$ and $\mathrm{TaON}$ with improved visible light photocatalytic activities. Dalton Trans. 2010, 39, 1488-1491. [CrossRef]

17. Pan, C.S.; Xu, J.; Wang, Y.J.; Li, D.; Zhu, Y.F. Dramatic activity of C3N4/BiPO4 photocatalyst with core/shell structure formed by self-assembly. Adv. Funct. Mater. 2012, 22, 1518-1524. [CrossRef]

18. Li, T.B.; Chen, G.; Zhou, C.; Shen, Z.Y.; Jin, R.C.; Sun, J.X. New photocatalyst BiOCl/BiOI composites with highly enhanced visible light photocatalytic performances. Dalton Trans. 2011, 40, 6751-6758. [CrossRef]

19. Liu, R.H.; Huang, H.; Li, H.T.; Liu, Y.; Zhong, J.; Li, Y.Y.; Zhang, S.; Kang, Z.H. Metal nanoparticle/carbon quantum dot composite as a photocatalyst for high-efficiency cyclohexane oxidation. ACS Catal. 2014, 4, 328-336. [CrossRef] 
20. Upadhyay, R.K.; Soin, N.; Roy, S.S. Role of graphene/metal oxide composites as photocatalysts, adsorbents and disinfectants in water treatment: A review. RSC Adv. 2014, 4, 3823-3851. [CrossRef]

21. Xiang, Q.J.; Yu, J.G.; Jaroniec, M. Graphene-based semiconductor photocatalysts. Chem. Soc. Rev. 2012, 41, 782-796. [CrossRef]

22. Zhang, N.; Liu, S.Q.; Xu, Y.J. Recent progress on metal core@semiconductor shell nanocomposites as a promising type of photocatalyst. Nanoscale 2012, 4, 2227-2238. [CrossRef]

23. Zhang, H.; Lv, X.J.; Li, Y.M.; Wang, Y.; Li, J.H. P25-graphene composite as a high performance photocatalyst. ACS Nano 2010, 4, 380-386. [CrossRef]

24. Giovannetti, R.; Rommozzi, E.; Zannotti, M.; D'Amato, C.A.; Ferraro, S.; Cespi, M.; Bonacucina, G.; Minicucci, M.; Di Cicco, A. Exfoliation of graphite into graphene in aqueous solution: an application as graphene $/ \mathrm{TiO}_{2}$ nanocomposite to improve visible light photocatalytic activity. RSC Adv. 2016, 6, 93048-93055. [CrossRef]

25. Giovannetti, R.; Rommozzi, E.; Zannotti, M.; D'Amato, C.A. Recent advances in graphene based $\mathrm{TiO}_{2}$ nanocomposites $\left(\mathrm{GTiO}_{2} \mathrm{Ns}\right)$ for photocatalytic degradation of synthetic dyes. Catalysts 2017, 7, 305. [CrossRef]

26. Rommozzi, E.; Zannotti, M.; Giovannetti, R.; D'Amato, C.A.; Ferraro, S.; Minicucci, M.; Gunnella, R.; Di Cicco, A. Reduced graphene oxide $/ \mathrm{TiO}_{2}$ nanocomposite: from synthesis to characterization for efficient visible light photocatalytic applications. Catalysts 2018, 8, 598. [CrossRef]

27. Zhang, N.; Zhang, Y.H.; Xu, Y.J. Recent progress on graphene-based photocatalysts: Current status and future perspectives. Nanoscale 2012, 4, 5792-5813. [CrossRef] [PubMed]

28. Akhavan, O. Graphene nanomesh by ZnO nanorod photocatalysts. ACS Nano 2010, 4, 4174-4180. [CrossRef] [PubMed]

29. Zhang, N.; Yang, M.Q.; Liu, S.Q.; Sun, Y.G.; Xu, Y.J. Waltzing with the versatile platform of graphene to synthesize composite photocatalysts. Chem. Rev. 2015, 115, 10307-10377. [CrossRef] [PubMed]

30. Shanmugam, S.; Gabashvili, A.; Jacob, D.S.; Yu, J.C.; Gedanken, A. Synthesis and characterization of $\mathrm{TiO}_{2} @ \mathrm{C}$ core-shell composite nanoparticles and evaluation of their photocatalytic activities. Chem. Mater. 2006, 18, 2275-2282. [CrossRef]

31. Sullivan, J.A.; Neville, E.M.; Herron, R.; Thampi, K.R.; Donal MacElroy, J.M. Routes to visible light active C-doped $\mathrm{TiO}_{2}$ photocatalysts using carbon atoms from the Ti precursors. J. Photochem. Photobiol. A Chem. 2014, 289, 60-65. [CrossRef]

32. Moghaddam, H.A.; Jafari, S.; Mohammadi, M.R. Enhanced efficiency of over $10 \%$ in dye-sensitized solar cells through $\mathrm{C}$ and $\mathrm{N}$ single- and co-doped $\mathrm{TiO}_{2}$ single-layer electrodes. New J. Chem. 2017, 41, 9453-9460. [CrossRef]

33. Noorimotlagh, Z.; Kazeminezhad, I.; Jaafarzadeh, N.; Ahmadi, M.; Ramezani, Z.; Martinez, S.S. The visible-light photodegradation of nonylphenol in the presence of carbon-doped $\mathrm{TiO}_{2}$ with rutile/anatase ratio coated on GAC: Effect of parameters and degradation mechanism. J. Hazard. Mater. 2018, 350, 108-120. [CrossRef]

34. Wu, X.Y.; Yin, S.; Dong, Q.; Sato, T. Blue/green/red colour emitting up-conversion phosphors coupled $\mathrm{C}-\mathrm{TiO}_{2}$ composites with UV, visible and NIR responsive photocatalytic performance. Appl. Catal. B Environ. 2014, 156-157, 257-264. [CrossRef]

35. Huang, Q.W.; Tian, S.Q.; Zeng, D.W.; Wang, X.X.; Song, W.L.; Li, Y.Y.; Xiao, W.; Xie, C.S. Enhanced photocatalytic activity of chemically bonded $\mathrm{TiO}_{2}$ /graphene composites based on the effective interfacial charge transfer through C-Ti bond. ACS Catal. 2013, 3, 1477-1485. [CrossRef]

36. Wang, S.; Zhao, L.; Bai, L.N.; Yan, J.M.; Jiang, Q.; Lian, J.S. Enhancing photocatalytic activity of disorder engineered $\mathrm{C} / \mathrm{TiO}_{2}$ and $\mathrm{TiO}_{2}$ nanoparticles. J. Mater. Chem. A 2014, 2, 7439-7445. [CrossRef]

37. Zhou, W.; Liu, Y.; Zhang, Y.Z.; Yang, G.; Deng, S.H.; Shen, F.; Peng, H.; Wang, L.L. Novel multi-layer cross-linked $\mathrm{TiO}_{2} / \mathrm{C}$ nanosheets and their photocatalytic properties. New J. Chem. 2014, 38, 1647-1654. [CrossRef]

38. Lin, Y.T.; Weng, C.H.; Chen, F.Y. Key operating parameters affecting photocatalytic activity of visible-light-induced $\mathrm{C}$-doped $\mathrm{TiO}_{2}$ catalyst for ethylene oxidation. Chem. Eng. J. 2014, 248, 175-183. [CrossRef]

39. Hassan, M.E.; Cong, L.; Liu, G.L.; Zhu, D.W.; Cai, J.B. Synthesis and characterization of C-doped $\mathrm{TiO}_{2}$ thin films for visible-light-induced photocatalytic degradation of methyl orange. Appl. Surf. Sci. 2014, 294, 89-94. [CrossRef] 
40. Lu, J.; Wang, Y.; Huang, J.F.; Fei, J.; Cao, L.Y.; Li, C.Y. In situ synthesis of mesoporous C-doped TiO 2 single crystal with oxygen vacancy and its enhanced sunlight photocatalytic properties. Dyes Pigments 2017, 144, 203-211. [CrossRef]

41. Dong, F.; Wang, H.Q.; Wu, Z.B. One-step “green" synthetic approach for mesoporous c-doped titanium dioxide with efficient visible light photocatalytic activity. J. Phys. Chem. C 2009, 113, 16717-16723. [CrossRef]

42. Dong, F.; Guo, S.; Wang, H.Q.; Li, X.F.; Wu, Z.B. Enhancement of the visible light photocatalytic activity of C-doped $\mathrm{TiO}_{2}$ nanomaterials prepared by a green synthetic approach. J. Phys. Chem. C 2011, 115, 13285-13292. [CrossRef]

43. Zhou, G.B.; Liu, X.W.; Nan, C.Y.; Liu, Y.X.; Wang, D.S.; Chen, X.Q. C/N-sensitized self-assembly of mesostructured $\mathrm{TiO}_{2}$ nanospheres with significantly enhanced photocatalytic activity. New J. Chem. 2013, 37, 2582-2588. [CrossRef]

44. Shi, J.W.; Chen, J.W.; Cui, H.J.; Fu, M.L.; Luo, H.Y.; Xu, B.; Ye, Z.L. One template approach to synthesize C-doped titania hollow spheres with high visible-light photocatalytic activity. Chem. Eng. J. 2012, 195-196, 226-232. [CrossRef]

45. Zhang, Y.; Zhao, Z.Y.; Chen, J.R.; Cheng, L.; Chang, J.; Sheng, W.C.; Hu, C.Y.; Cao, S.S. C-doped hollow $\mathrm{TiO}_{2}$ spheres: In situ synthesis, controlled shell thickness, and superior visible-light photocatalytic activity. Appl. Catal. B Environ. 2015, 165, 715-722. [CrossRef]

46. Xie, C.; Yang, S.H.; Li, B.B.; Wang, H.K.; Shi, J.W.; Li, G.D.; Niu, C.M. C-doped mesoporous anatase $\mathrm{TiO}_{2}$ comprising $10 \mathrm{~nm}$ crystallites. J. Coll. Interface Sci. 2016, 476, 1-8. [CrossRef] [PubMed]

47. Purbia, R.; Borah, R.; Paria, S. Carbon-doped mesoporous anatase $\mathrm{TiO}_{2}$ multi-tubes nanostructures for highly improved visible light photocatalytic activity. Inorg. Chem. 2017, 56, 10107-10116. [CrossRef] [PubMed]

48. Shi, Z.J.; Ma, M.G. Synthesis, structure, and applications of lignin-based carbon materials: A review. Sci. Adv. Mater. 2019, 11, 18-32. [CrossRef]

49. Liu, S.; Ma, C.; Ma, M.G.; Li, J.F. Recent advances in carbon nanomaterials derived from biomass. Sci. Adv. Mater. 2019, 11, 5-17. [CrossRef]

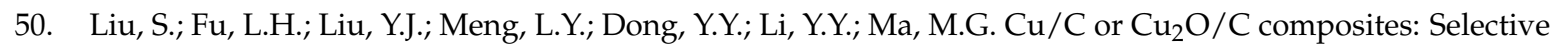
synthesis, characterization, and applications in water treatment. Sci. Adv. Mater. 2016, 8, $2045-2053$. [CrossRef]

51. Wang, B.; Liu, B.; Ji, X.X.; Ma, M.G. Synthesis, characterization, and photocatalytic properties of bamboo charcoal $/ \mathrm{TiO}_{2}$ composites using four sizes powder. Materials 2018, 11, 670. [CrossRef]

52. Liu, B.; Liu, S.; Meng, L.Y.; Li, Y.Y.; Wang, B.; Ma, M.G. Microwave-hydrothermal synthesis and photocatalytic properties of biomass charcoal $/ \mathrm{TiO}_{2}$ nanocomposites. J. Saudi Chem. Soc. 2018, 22, 509-518. [CrossRef]

53. Liu, X.; Li, Y.L.; Yang, J.; Wang, B.; Ma, M.G.; Xu, F.; Sun, R.C.; Zhang, X.M. Enhanced photocatalytic activity of CdS-decorated $\mathrm{TiO}_{2}$ / carbon core-shell microspheres derived from microcrystalline cellulose. Materials 2016, 9, 245. [CrossRef]

54. Wang, X.P.; Lim, T.T. Solvothermal synthesis of $\mathrm{C}-\mathrm{N}$ codoped $\mathrm{TiO}_{2}$ and photocatalytic evaluation for bisphenol A degradation using a visible-light irradiated LED photoreactor. Appl. Catal. B Environ. 2010, 100, 355-364. [CrossRef]

55. Dolat, D.; Quici, N.; Kusiak-Nejman, E.; Morawski, A.W.; Puma, G.L. One-step, hydrothermal synthesis of nitrogen, carbon co-doped titanium dioxide $\left.(\mathrm{N}, \mathrm{C} \mathrm{TiO})_{2}\right)$ photocatalysts. Effect of alcohol degree and chain length as carbon dopant precursors on photocatalytic activity and catalyst deactivation. Appl. Catal. B Environ. 2012, 115-116, 81-89. [CrossRef]

56. Wang, D.H.; Jia, L.; Wu, X.L.; Lu, L.Q.; Xu, A.W. One-step hydrothermal synthesis of N-doped $\mathrm{TiO}_{2} / \mathrm{C}$ nanocomposites with high visible light photocatalytic activity. Nanoscale 2012, 4, 576-584. [CrossRef]

57. Wu, D.Y.; Wang, L.Z. Low-temperature synthesis of anatase C-N-TiO 2 photocatalyst with enhanced visible-light-induced photocatalytic activity. Appl. Surf. Sci. 2013, 271, 357-361. [CrossRef]

58. Ming, H.; Huang, H.; Pan, K.M.; Li, H.T.; Liu, Y.; Kang, Z.H. C/TiO 2 nanohybrids co-doped by $\mathrm{N}$ and their enhanced photocatalytic ability. J. Solid State Chem. 2012, 192, 305-311. [CrossRef]

59. Wang, M.G.; Han, J.; Hu, Y.M.; Guo, R. Mesoporous C, N-codoped $\mathrm{TiO}_{2}$ hybrid shells with enhanced visible light photocatalytic performance. RSC Adv. 2017, 7, 15513-15520. [CrossRef] 
60. Peng, Y.P.; Chen, H.L.; Huang, C.P. The synergistic effect of photoelectrochemical (PEC) reactions exemplified by concurrent perfluorooctanoic acid (PFOA) degradation and hydrogen generation over carbon and nitrogen codoped $\mathrm{TiO}_{2}$ nanotube arrays (C-N-TNTAs) photoelectrode. Appl. Catal. B-Environ. 2017, 209, 437-446. [CrossRef]

61. Venkatkarthick, R.; Davidson, D.J.; Vasudevan, S.; Sozhan, G.; Ravichandran, S. An investigation of interfacial and photoelectrochemical performance of thermally prepared $\mathrm{C}, \mathrm{N}$-codoped $\mathrm{TiO}_{2}$ photoanodes for water splitting. Chemistryselect 2017, 2, 288-294. [CrossRef]

62. Zhang, X.Y.; Zhang, Y.; Zhou, L.G.; Li, X.K.; Guo, X.Y. In situ C,N-codoped mesoporous $\mathrm{TiO}_{2}$ nanocrystallites with high surface areas and worm-like structure for efficient photocatalysis. J. Porous Mater. 2018, 25, 571-579. [CrossRef]

63. Wang, Q.; Jiang, Z.Y.; Wang, Y.B.; Chen, D.M.; Yang, D. Photocatalytic properties of porous C-doped TiO 2 and $\mathrm{Ag} / \mathrm{C}$-doped $\mathrm{TiO}_{2}$ nanomaterials by eggshell membrane templating. J. Nanopart. Res. 2009, 11, 375-384. [CrossRef]

64. Zhang, L.; Han, M.D.; Tan, O.K.; Tse, M.S.; Wang, Y.X.; Sze, C.C. Facile fabrication of Ag/C-TiO 2 nanoparticles with enhanced visible light photocatalytic activity for disinfection of Escherichia coli and Enterococcus faecalis. J. Mater. Chem. B 2013, 1, 564-570. [CrossRef]

65. Zhang, J.; Pan, C.X.; Fang, P.F.; Wei, J.H.; Xiong, R. Mo + C co-doped $\mathrm{TiO}_{2}$ using thermal oxidation for enhancing photocatalytic activity. ACS Appl. Mater. Interfaces 2010, 2, 1173-1176. [CrossRef] [PubMed]

66. Wu, X.Y.; Yin, S.; Dong, Q.; Guo, C.S.; Kimura, T.; Matsushita, J.; Sato, T. Photocatalytic properties of Nd and $\mathrm{C}$ codoped $\mathrm{TiO}_{2}$ with the whole range of visible light absorption. J. Phys. Chem. C 2013, 117, 8345-8352. [CrossRef]

67. Yang, D.; Li, Y.B.; Tong, Z.W.; Sun, Y.Y.; Jiang, Z.Y. One-pot fabrication of C-Fe-co-doped $\mathrm{TiO}_{2}$ sheets with dominant $\{001\}$ facets for enhanced visible-light photocatalytic activity. Ind. Engineer. Chem. Res. 2014, 53, 19249-19256.

68. Guo, M.L. Synergistic effect of $\mathrm{C}$, Ag-codoped $\mathrm{TiO}_{2}$ photocatalyst within the GGA plus U framework. RSC Adv. 2015, 5, 434-439. [CrossRef]

69. Wu, Y.; Tian, Y.; Zheng, S.K. First principles study on the electronic structure and optical property of Nd-C codoped anatase $\mathrm{TiO}_{2}$. Mater.-Rio De Janeiro 2016, 21, 301-306.

70. Pham, T.D.; Lee, B.K. Novel capture and photocatalytic conversion of $\mathrm{CO}_{2}$ into solar fuels by metals co-doped $\mathrm{TiO}_{2}$ deposited on PU under visible light. Appl. Catal. A-Gen. 2017, 529, 40-48. [CrossRef]

71. Nyamukamba, P.; Tichagwa, L.; Mamphweli, S.; Petrik, L. Silver/carbon codoped titanium dioxide photocatalyst for improved dye degradation under visible light. Int. J. Photoenergy 2017, 2017, 3079276. [CrossRef]

72. Xu, H.; Zhang, L.Z. Controllable one-pot synthesis and enhanced visible light photocatalytic activity of Tunable C-Cl-Co-doped $\mathrm{TiO}_{2}$ nanocrystals with high surface area. J. Phys. Chem. C 2010, 114, 940-946. [CrossRef]

73. Bai, H.W.; Kwan, K.S.Y.; Liu, Z.Y.; Song, X.X.; Lee, S.S.; Sun, D.D. Facile synthesis of hierarchically meso/nanoporous S- and C-co-doped $\mathrm{TiO}_{2}$ and its high photocatalytic efficiency in $\mathrm{H}_{2}$ generation. Appl. Catal. B Environ. 2013, 129, 294-300. [CrossRef]

74. Xu, P.; Xu, T.; Lu, J.; Gao, S.M.; Hosmane, N.S.; Huang, B.B.; Dai, Y.; Wang, Y.B. Visible-light-driven photocatalytic S- and C-codoped meso/nanoporous $\mathrm{TiO}_{2}$. Energy Environ. Sci. 2010, 3, 1128-1134. [CrossRef]

75. Lei, X.F.; Xue, X.X.; Yang, H.; Chen, C.; Li, X.; Niu, M.C.; Gao, X.Y.; Yang, Y.T. Effect of calcination temperature on the structure and visible-light photocatalytic activities of $\left(\mathrm{N}, \mathrm{S}\right.$ and $\mathrm{C}$ ) co-doped $\mathrm{TiO}_{2}$ nano-materials. Appl. Surf. Sci. 2015, 332, 172-180. [CrossRef]

76. Li, Y.H.; Sun, Y.J.; Dong, F.; Ho, W.K. Enhancing the photocatalytic activity of bulk g- $\mathrm{C}_{3} \mathrm{~N}_{4}$ by introducing mesoporous structure and hybridizing with grapheme. J. Coll. Interface Sci. 2014, 436, 29-36. [CrossRef] [PubMed]

77. Shi, L.; Liang, L.; Ma, J.; Wang, F.X.; Sun, J.M. Remarkably enhanced photocatalytic activity of ordered mesoporous carbon/g-C3N4 composite photocatalysts under visible light. Dalton Trans. 2014, 43, 7236-7244. [CrossRef]

78. Zou, Y.J.; Shi, J.W.; Ma, D.D.; Fan, Z.Y.; Lu, L.; Niu, C.M. In situ synthesis of C-doped $\mathrm{TiO}_{2} @ g-\mathrm{C}_{3} \mathrm{~N}_{4}$ core-shell hollow nanospheres with enhanced visible-light photocatalytic activity for $\mathrm{H}_{2}$ evolution. Chem. Eng. J. 2017, 322, 435-444. [CrossRef] 
79. Li, Y.P.; Wu, S.L.; Huang, L.Y.; Wang, J.L.; Xu, H.; Li, H.M. Synthesis of carbon-doped g-C ${ }_{3} \mathrm{~N}_{4}$ composites with enhanced visible-light photocatalytic activity. Mater. Lett. 2014, 137, 281-284. [CrossRef]

80. Zhou, Y.J.; Zhang, L.X.; Huang, W.M.; Kong, Q.L.; Fan, X.Q.; Wang, M.; Shi, J.L. N-doped graphitic carbon-incorporated $\mathrm{g}_{-} \mathrm{C}_{3} \mathrm{~N}_{4}$ for remarkably enhanced photocatalytic $\mathrm{H}_{2}$ evolution under visible light. Carbon 2016, 99, 111-117. [CrossRef]

81. Wang, F.L.; Chen, P.; Feng, Y.P.; Xie, Z.J.; Liu, Y.; Su, Y.H.; Zhang, Q.X.; Wang, Y.F.; Yao, K.; Lv, W.Y. Facile synthesis of $\mathrm{N}$-doped carbon dots $/ \mathrm{g}-\mathrm{C}_{3} \mathrm{~N}_{4}$ photocatalyst with enhanced visible-light photocatalytic activity for the degradation of indomethacin. Appl. Catal. B-Environ. 2017, 207, 103-113. [CrossRef]

82. Wen, J.Q.; Xie, J.; Yang, Z.H.; Shen, R.C.; Li, H.Y.; Luo, X.Y.; Chen, X.B.; Li, X. Fabricating the Robust g-C $\mathrm{C}_{4}$ Nanosheets/carbons/NiS multiple heterojunctions for enhanced photocatalytic $\mathrm{H}_{2}$ generation: An insight into the trifunctional roles of nanocarbons. ACS Sustain. Chem. Eng. 2017, 5, 2224-2236. [CrossRef]

83. Gong, Y.; Zhao, X.; Zhang, H.; Yang, B.; Xiao, K.; Guo, T.; Zhang, J.J.; Shao, H.X.; Wang, Y.B.; $\mathrm{Yu}, \mathrm{G}$. MOF-derived nitrogen doped carbon modified $\mathrm{g}-\mathrm{C}_{3} \mathrm{~N}_{4}$ heterostructure composite with enhanced photocatalytic activity for bisphenol A degradation with peroxymonosulfate under visible light irradiation. Appl. Catal. B-Environ. 2018, 233, 35-45. [CrossRef]

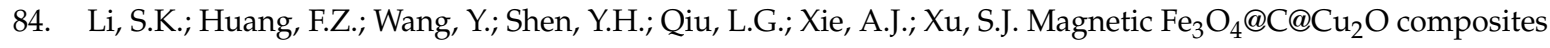
with bean-like core/shell nanostructures: Synthesis, properties and application in recyclable photocatalytic degradation of dye pollutants. J. Mater. Chem. 2011, 21, 7459-7466. [CrossRef]

85. Zhou, M.J.; Hu, Y.; Liu, Y.; Yang, W.L.; Qian, H.S. Microwave-assisted route to fabricate coaxial ZnO/C/CdS nanocables with enhanced visible light-driven photocatalytic activity. CrystEngComm 2012, 14, 7686-7693. [CrossRef]

86. Cai, J.B.; Wu, X.Q.; Li, S.X.; Zheng, F.Y.; Zhu, L.C.; Lai, Z.H. Synergistic effect of double-shelled and sandwiched $\mathrm{TiO}_{2} @ \mathrm{Au} @ \mathrm{C}$ hollow spheres with enhanced visible-light-driven photocatalytic activity. ACS Appl. Mater. Interfaces 2015, 7, 3764-3772. [CrossRef]

87. Yang, S.J.; Im, J.H.; Kim, T.; Lee, K.; Park, C.R. MOF-derived ZnO and ZnO@C composites with high photocatalytic activity and adsorption capacity. J. Hazard. Mater. 2011, 186, 376-382. [CrossRef] [PubMed]

88. Zhang, P.; Li, B.B.; Zhao, Z.B.; Yu, C.; Hu, C.; Wu, S.J.; Qiu, J.S. Furfural-induced hydrothermal synthesis of ZnO@C gemel hexagonal microrods with enhanced photocatalytic activity and stability. ACS Appl. Mater. Interfaces 2014, 6, 8560-8566. [CrossRef] [PubMed]

89. Ma, S.S.; Xue, J.J.; Zhou, Y.M.; Zhang, Z.W.; Wu, X. A facile route for the preparation of ZnO/C composites with high photocatalytic activity and adsorption capacity. CrystEngComm 2014, 16, 4478. [CrossRef]

90. Mu, J.B.; Guo, Z.C.; Che, H.W.; Zhang, X.L.; Bai, Y.M.; Hou, J.X. Electrospinning of C-doped ZnO nanofibers with high visible-light photocatalytic activity. J. Sol-Gel Sci. Technol. 2016, 78, 99-109. [CrossRef]

91. Wang, S.B.; Zhang, X.W.; Li, S.; Fang, Y.; Pan, L.; Zou, J.J. C-doped ZnO ball-in-ball hollow microspheres for efficient photocatalytic and photoelectrochemical applications. J. Hazard. Mater. 2017, 331, 235-245. [CrossRef]

92. Chen, Y.L.; Cao, X.X.; Kuang, J.D.; Chen, Z.; Chen, J.L.; Lin, B.Z. The gas-phase photocatalytic mineralization of benzene over visible-light-driven $\mathrm{Bi}_{2} \mathrm{WO}_{6} @ \mathrm{C}$ microspheres. Catal. Commun. 2010, 12, 247-250. [CrossRef]

93. Sun, H.G.; Zhao, X.; Zhang, L.; Fan, W.L. Origin of the enhanced visible photocatalytic activity in (N, C)-codoped ZnS studied from density functional theory. J. Phys. Chem. C 2011, 115, 2218-2227. [CrossRef]

94. Lu, H.X.; Lei, J.; Li, X.X.; Shao, G.; Hou, T.C.; Fan, B.B.; Chen, D.L.; Zhang, L.W.; Wang, H.L.; $\mathrm{Xu}, \mathrm{H}$.L. Synthesis and characterization of carbon-doped $\mathrm{ZnSn}(\mathrm{OH})_{6}$ with enhanced photoactivity by hydrothermal method. Cryst. Res. Technol. 2016, 51, 11-15. [CrossRef]

(C) 2018 by the authors. Licensee MDPI, Basel, Switzerland. This article is an open access article distributed under the terms and conditions of the Creative Commons Attribution (CC BY) license (http:// creativecommons.org/licenses/by/4.0/). 